Article

\title{
Fine Surveying and 3D Modeling Approach for Wooden Ancient Architecture via Multiple Laser Scanner Integration
}

\author{
Qingwu Hu ${ }^{1, \dagger}$, Shaohua Wang ${ }^{2, *+}$, Caiwu Fu ${ }^{3, \dagger}$, Mingyao Ai ${ }^{1, \dagger}$, Dengbo Yu ${ }^{1, \dagger}$ \\ and Wende Wang ${ }^{3,+}$ \\ 1 School of Remote Sensing and Information Engineering, Wuhan University, No.129, Luoyu Road, \\ Wuhan 430079, China; huqw@whu.edu.cn (Q.H.); aimingyao@whu.edu.cn (M.A.); \\ 2012202130005@whu.edu.cn (D.Y.) \\ 2 School of International Software, Wuhan University, No.129, Luoyu Road, Wuhan 430079, China \\ 3 Institute of National Culture Development, Wuhan University, Luojiashan, Wuhan 430070, China; \\ cwfu@whu.edu.cn (C.F.); qimingxing@whu.edu.cn (W.W.) \\ * Correspondence: shwang@whu.edu.cn; Tel./Fax: +86-27-6877-8117 \\ + These authors contributed equally to this work.
}

Academic Editors: Diego Gonzalez-Aguilera, Fabio Remondino, Randolph H. Wynne and Prasad S. Thenkabail Received: 30 November 2015; Accepted: 1 March 2016; Published: 25 March 2016

\begin{abstract}
A multiple terrestrial laser scanner (TLS) integration approach is proposed for the fine surveying and 3D modeling of ancient wooden architecture in an ancient building complex of Wudang Mountains, which is located in very steep surroundings making it difficult to access. Three-level TLS with a scalable measurement distance and accuracy is presented for data collection to compensate for data missed because of mutual sheltering and scanning view limitations. A multi-scale data fusion approach is proposed for data registration and filtering of the different scales and separated 3D data. A point projection algorithm together with point cloud slice tools is designed for fine surveying to generate all types of architecture maps, such as plan drawings, facade drawings, section drawings, and doors and windows drawings. The section drawings together with slicing point cloud are presented for the deformation analysis of the building structure. Along with fine drawings and laser scanning data, the 3D models of the ancient architecture components are built for digital management and visualization. Results show that the proposed approach can achieve fine surveying and 3D documentation of the ancient architecture within $3 \mathrm{~mm}$ accuracy. In addition, the defects of scanning view and mutual sheltering can overcome to obtain the complete and exact structure in detail.
\end{abstract}

Keywords: ancient wooden architecture; terrestrial laser scanning; documenting; fine surveying; 3D modeling; point cloud projection; point cloud slicing

\section{Introduction}

The architecture of China is as old as its civilization. Together with European and Arabian architecture, ancient Chinese architecture is an important component of the world architectural system $[1,2]$. Since the Tang Dynasty, Chinese architecture has significantly influenced the architectural styles of Korea, Vietnam, and Japan. Ancient Chinese architecture mainly involved timberwork. Wooden posts, beams, lintels, and joists make up the framework of a house [3,4]. The specialty of woodworking requires the adoption of antisepsis methods, which eventually developed into the respective architectural painting decorations of China. Colored glaze roofs, windows with exquisite applique designs, and beautiful flower patterns on wooden pillars reflect the high level of craftsmanship and rich imagination. 
Unlike other building construction materials, old wooden structures often do not survive because they are vulnerable to weathering and fires and are naturally subjected to rotting over time. Consequently, only a few examples of ancient wooden architecture exist today [5-7]. YuZhen Palace, which was included in the World Heritage List, was a famous ancient wooden architecture complex in Wudang Mountain. It was built in 1417 to represent the Taoism culture. On 19 January 2003, a fire turned YuZhen Palace into ashes. Chinese traditional ancient wooden architecture is an important cultural heritage; thus, its protection, repair, maintenance, and restoration is a significant challenge [8,9].

Fine surveying and mapping to generate 3D models of historical buildings by obtaining all types of maps and drawings is an important task for digital protection projects and continuous monitoring of ancient wooden architecture [1-12]. Fine maps, drawings, and photorealistic models can provide high geometric accuracy and detail of the architectural layout and structure. For the past two decades, total station surveying and close-range photogrammetry were traditionally used for the required data collection of historical buildings [13-16]. The 3D data collection based on laser scanning has made great progress in the quick and reliable fine surveying and 3D documentation of heritage sites by obtaining millions of 3D points to effectively generate a dense representation of the respective surface geometry $[16,17]$.

Laser scanning techniques can create the 3D nature of archaeological objects that vary in size and shape, ranging from something as small as a human molar to objects as large as a building. Terrestrial laser scanning has been widely adopted in archaeology site surveys and 3D documentation, particularly in projects dealing with ancient architecture [18-21]. Several surveying and digital heritage projects focusing on the use of laser scanning technologies for 3D modeling of heritage sites can be seen in literature [22-28]. Recent studies on terrestrial laser scanning techniques have achieved great progress in 3D archaeological documentation. However, some limitations remain. The restrictions of scanning view and mutual sheltering lead to data being missed in terms of structural details, particularly for complex ancient architecture, thereby affecting the quality of the final 3D model $[29,30]$. Establishing proper approaches to TLS data collection and processing for the fine surveying and 3D modeling of complex archeological sites is challenging and valuable work, specifically in transforming these approaches from research to generally accepted techniques.

The work presented in this paper aims to overcome the scanning view restriction and mutual sheltering in difficult surveying surroundings to obtain fine surveying and 3D documentation of Chinese wooden architecture through the combination of different levels of terrestrial laser scanners. Three-level TLS with a scalable measurement distance and accuracy is presented for the data collection of the architecture to solve the problems of fine surveying and 3D documentation of the ancient building complex, which is constructed on the cliffs of Wudang Mountains. A multi-scale data fusion approach is proposed for laser scanning data registration and filtering. A laser scanning point projection algorithm together with point cloud slice tools is designed for the fine surveying of the ancient architecture to generate all types of architecture maps, such as plan drawings, facade drawings, section drawings, and doors and windows drawings. The section drawings together with slicing point cloud are presented for the deformation analysis of the building structure. The 3D models of the ancient architecture components are built for digital management, research, and visualization through fine drawings and laser scanning data.

\section{Background}

\subsection{Liangyi Temple in Wudang Mountains}

Wudang Mountains are located in Shiyan, Hubei Province in Central China and are renowned for the practice of Tai Chi and Taoism. Liangyi Temple is the Buddhist counterpart of the Shaolin Monastery, which is affiliated with Chinese Chan Buddhism. A total of 53 ancient buildings and nine architectural sites were constructed from the early Tang Dynasty to the Yuan, Ming, and Qing dynasties. These structures are listed as World Heritage Sites because they include many Taoist monasteries and secular buildings, all of which have a profound influence on Chinese art and architecture. 
The existing Liangyi Temple, which was built on the South Cliff during the Yongle Period (1403-1424) and undertaken by Emperor Zhu Di in memory of his parents, is one of the extremely precious official wooden buildings in Wudang Mountains. It has maintained its original structure since its construction during the Ming Dynasty. It is located in the middle of a cliff, as presented in Figure 1a,c. The gate of Liangyi Temple is masterly built at its side by ancient designers, and its external veranda extends straight to the Tianyi Zhenqing Stone Hall, which was built during the Yuan Dynasty; its front Longtou Incense (as shown in Figure 1d), which faces the Golden Dome, shows the superb idea of ancient Chinese craftsmen and fully reflects the Taoist "Imitation of Nature" [31,32].

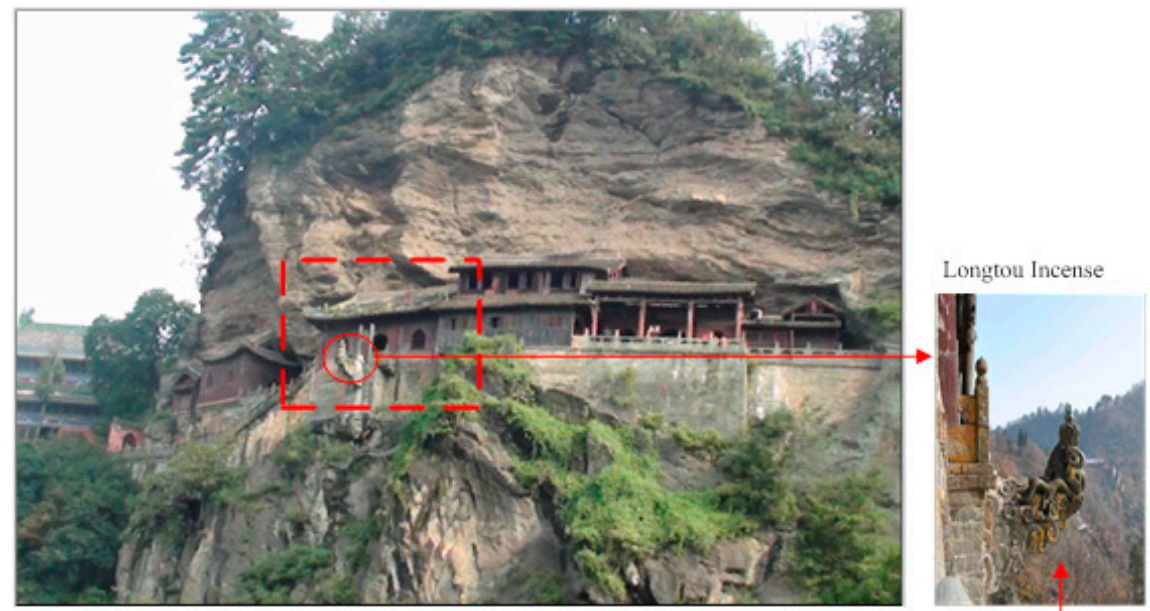

(a)

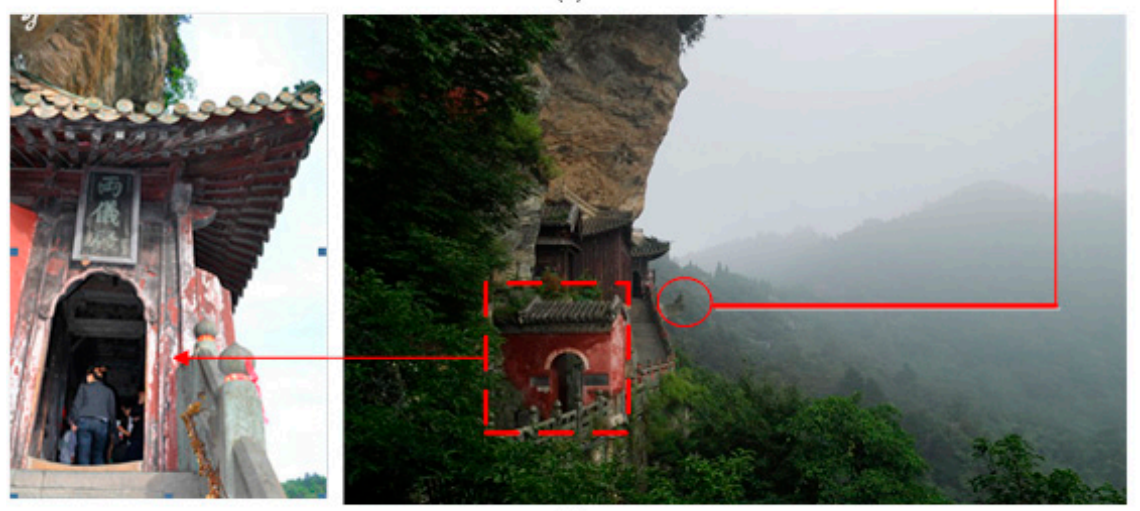

(b)

Figure 1. Ancient architecture of Liangyi Temple: (a) front side, (b) side face. The red dashed rectangle in (a) is the Liangyi Temple. The red dashed rectangle in $(\mathbf{b})$ is the gate door of Liangyi Temple. The red circle is Longtou Incense.

As shown in Figure 1, Liangyi Temple was built on a mountain cliff. It was one of the important royal Taoist architectural complexes in Wudang Mountains. The temple, which includes a gable and hip roof, a wooden structure, and a single building, was the best preserved Ming Dynasty architecture in Wudang Mountains. The construction of Liangyi Temple represents the outstanding achievement of Chinese architectural technology and art, which has great historical, scientific, and artistic value.

\subsection{Threats on Liangyi Temple}

As a world cultural heritage, Liangyi Temple faces huge challenges for its protection. Wudang Mountains are located in a subtropical monsoon climate zone. The mild and humid weather provides a suitable living environment for white ants. The wood components of Liangyi Temple have no resistance against moths. The wooden columns serve as the load-bearing structure and are easily infested by white ants, which cause structural deformation or collapse. Thus, the structure of the 
building should be monitored to protect the wooden Liangyi Temple by preventing its deformation. Another significant threat is fire. On 19 January 2003, a fire broke out in Wudang Mountains, causing another wooden historical building, namely, Yuzhen Palace, to burn to ashes $[9,33,34]$. The Longtou Incense in front of Liangyi Temple is a fire source, and frequent Taoist activities with joss candles and electrical lightings are potential fire risks. As an internationally renowned area of cultural heritage, Wudang Mountains were visited by more than 3,689,000 tourists by the end of July 2015. The large number of visitors and narrow visiting places present another threat to the building structure and body.

Given the aforementioned threats, the fine surveying, mapping, 3D documentation, and modeling for the digital protection of the wooden Liangyi Temple are necessary and valuable. The Chinese government started the "Compass Plan" through fine surveying and 3D documentation projects to prevent accidents with ancient architecture. Liangyi Temple was selected as a representation of ancient wooden architecture.

\subsection{Problems and Solution: Fine Surveying and 3D Documentation for Liangyi Temple}

In previous literature, terrestrial laser scanning technologies are widely used for the surveying and documentation of all types of archaeological sites, such as caves, natural landscapes, buildings, and tombs. The basic principle of the laser scanner is that it rapidly captures the shapes of objects through distance measurement at every pointing direction with a rotation mirror. The object should be in the direction of the laser point without any sheltering. Thus, scanning view restriction and mutual sheltering, which can affect the quality of 3D data, are more serious factors than weather and fogs $[28,29]$. Liangyi Temples only consist of two houses with an area of less than $50 \mathrm{~m}^{2}$. Except for the statues and tables, the standing place is less than $20 \mathrm{~m}^{2}$ with no more than a $1 \mathrm{~m}$ corridor. The complicated setting and complex building structure lead to the following problems in surveying and documentation via laser scanning:

(1) Missed corner data: The small and narrow standing place requires many stations of TLS, leading to serious missed 3D data with the restriction of scanning view, as shown in Figure 2.

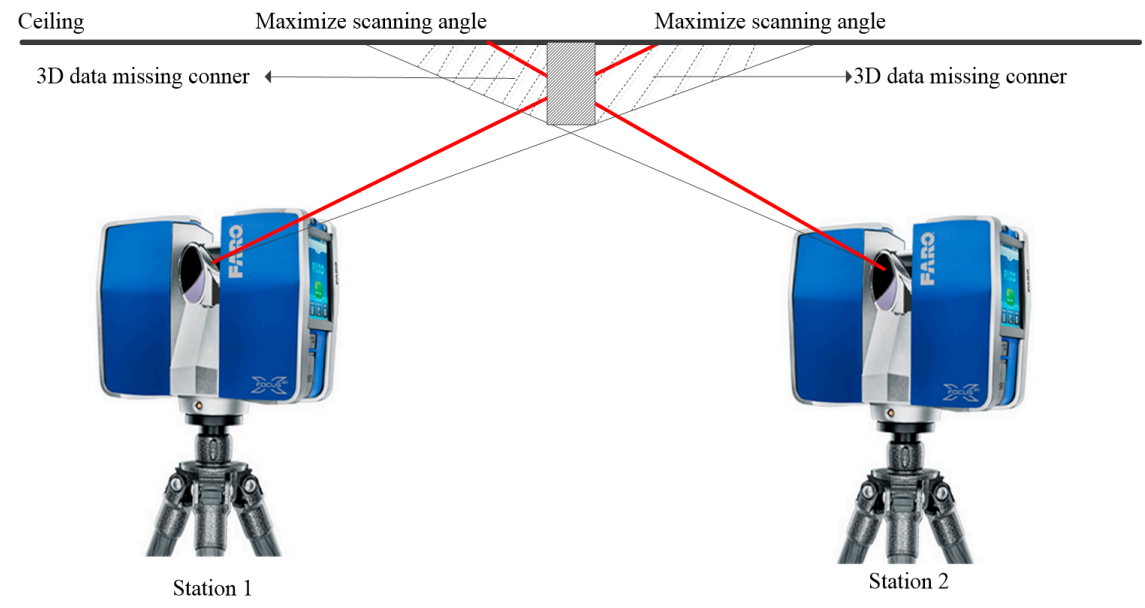

Figure 2. Blind corner in scanning of two stations.

Figure 2 shows that the intersection of ceiling and cantilever causes blind scanning of the two stations, and 3D data of the blind corner are missed. Numerous close scans should be set up to collect the missed 3D data of the blind corner.

(2) Incomplete 3D data of the structure: As a Taoism worship site, Liangyi Temple has many statues, tables, boxes, and ritual supplies. Mutual sheltering in the small space also causes another kind of incomplete 3D data for the structure measurement. Changing the scanning view or using a handheld laser scanner can limit the missed 3D data for the detailed architecture structure surveying. A special 
point cloud data processing approach should be designed to achieve precise structure surveying behind the sheltering objects with the adjacent 3D data, for example, the slicing of point cloud from a different angle to intersect the corner.

(3) Separated 3D data of the difficult scene: As introduced in Section 2.2, Liangyi Temple was constructed on a cliff. Thus, collecting the whole 3D data in one scene is impossible. The roof surface in the scene of the building and the inside of the building from the roof of the building cannot be seen. The front and back sides of the cliff have no space for TLS data collection. The only position from the gate to obtain 3D data of the building with its roof is also restricted by the scanning view. Thus, the whole scene of 3D data of the cliff terrain can only be collected from the front side of the cliff, which should be at the other peak opposite to the cliff. The 3D data of the roof must be collected at the top of the building. Data registration and fusion of the separated 3D data are other challenges for 3D documentation and fine surveying.

The unique and steep location of Liangyi Temple with its complicated layout and structure makes fine surveying and 3D documentation difficult using the current terrestrial laser scanning technique. The scalable and difficult scene must use different types of laser scanners to collect 3D data with minimal loss. Our solution is to integrate long-distance TLS, middle-range laser scanner, and a handheld scanner. The long-distance TLS (Riegl VZ 1000) will collect 3D data of the cliff terrain and the whole building. The middle-range laser scanner (Faro Focus 3D) will cover the building body and roof. The handheld scanner (Handyscan 3D) will be adopted for the architectural components and the scattered blind corner. All these separated 3D data should be registered well by their spatial relationship for further mapping and 3D modeling. The proposed idea is explained in Figure 3.

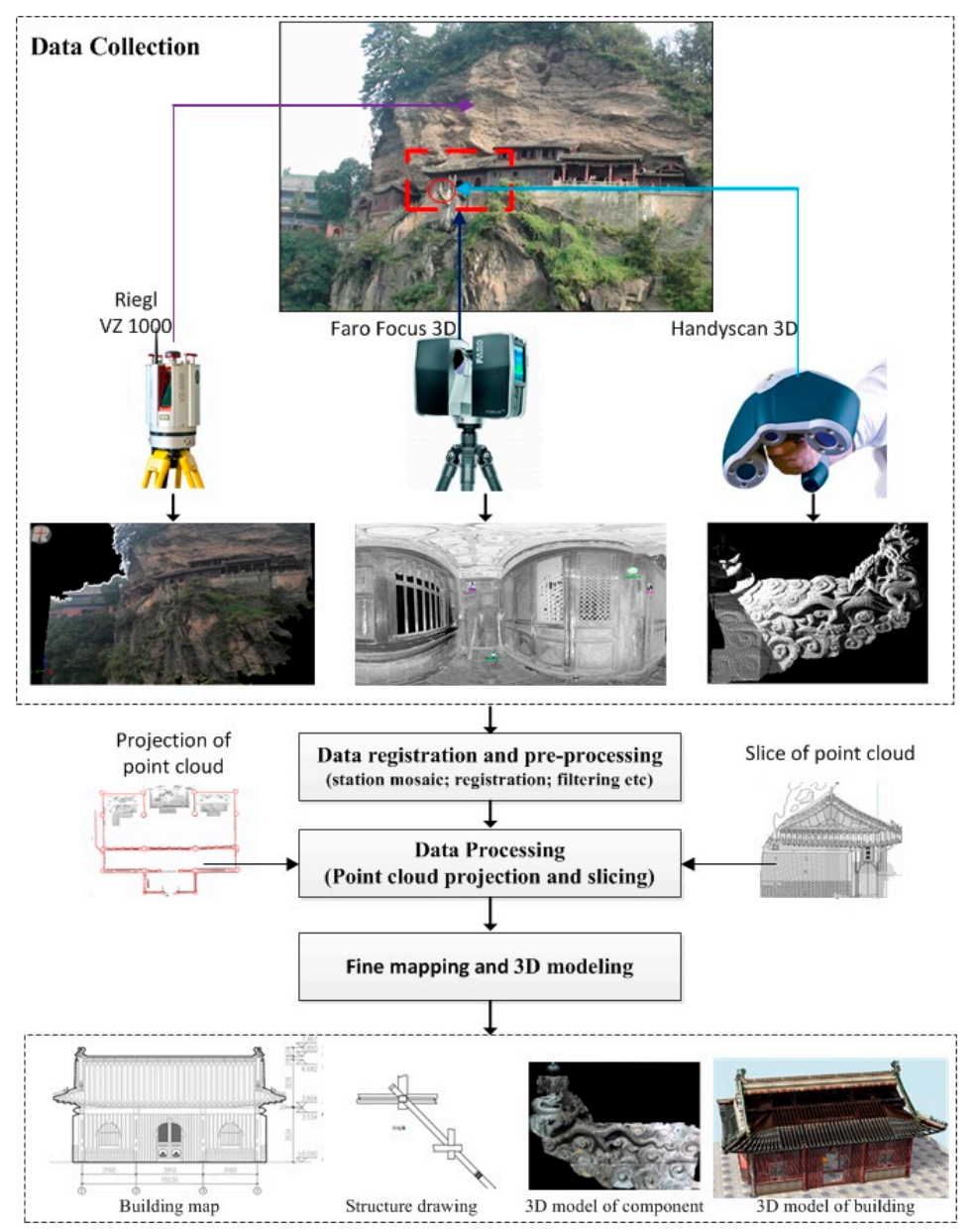

Figure 3. Proposed idea for the fine mapping and 3D documentation of Liangyi Temple. 
The proposed idea for the fine mapping and 3D modeling of Liangyi Temple includes data collection, 3D data registration and preprocessing, 3D data processing, fine mapping, and 3D modeling. The rest of this paper is organized as follows. Section 3 introduces the proposed idea in detail. Section 4 discusses the final results. Finally, Section 5 presents the conclusions of the proposed approach and future work.

\section{Methodology}

The proposed approach defines an optimized terrestrial laser scanning flowchart for the fine surveying and 3D documentation of Liangyi Temple when compared with the current method used for archaeological sites. Multiple laser scanner integration also brings related data processing methods, which are presented in Sections 3.2-4.

\subsection{D Data Collection Based on Multiple Laser Scanner Integration}

The different types of terrestrial laser scanning were applied according to local conditions. Differential GPS (DGPS) and total station were adopted to ensure the orientation and registration of different 3D datasets in a common coordinate system by measuring the ground control points (GCPs) and target points of TLS. The field data collection workflow is shown in Figure 4.

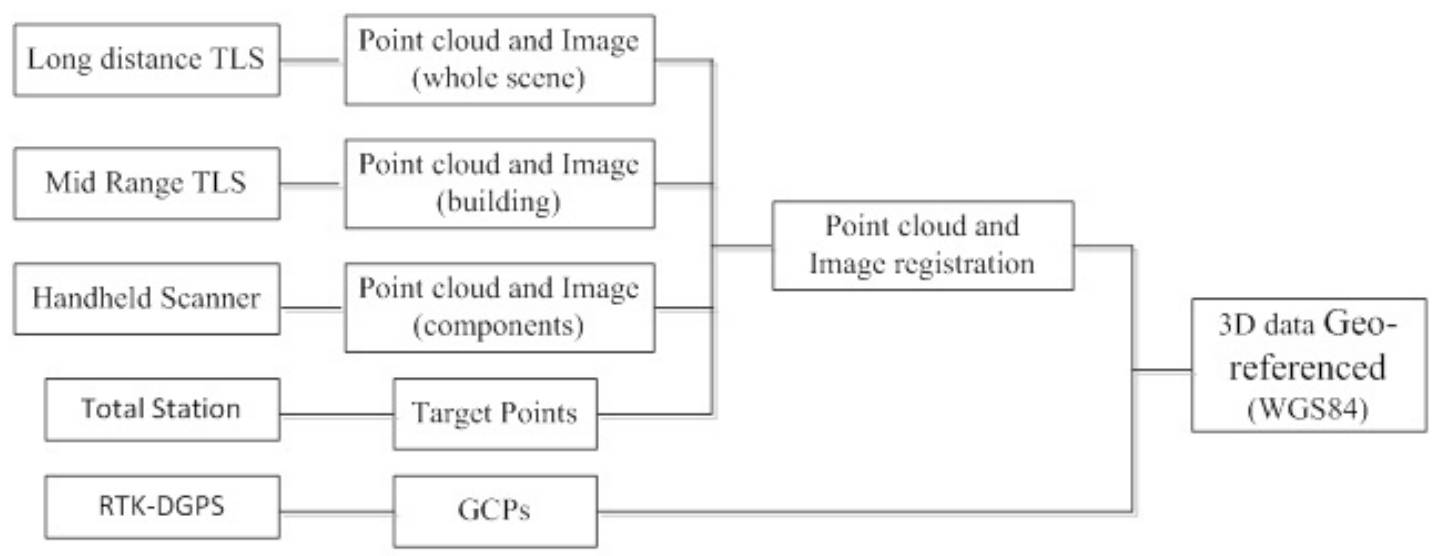

Figure 4. Workflow of field data collection.

(1) Control points and target point measurements

The GCPs were measured with DGPS in real-time kinematic mode (DGPS-RTK) in the WGS84 coordinate system with respective 3D accuracies of 10 and $15 \mathrm{~mm}$ in the horizontal and vertical directions after net adjustment. Three types of targets were adopted for the laser scanning data registration. One was a retro-reflecting circle provided by Riegl $\mathrm{GmbH}$. The second was a reference sphere from Faro Focus 3D. The last one was a rectangle white-black cardboard. The target points with reference sphere were used for point cloud registration station by station, and their coordinates do not need to be measured. The target points with retro-reflecting circle and rectangle white-black cardboard were used for the long-distance Riegl point cloud registration together with the middle-distance point cloud from Faro Focus 3D. Thus, they needed absolute coordinates. Total station was adopted to survey all these target points based on GCPs measured with DGPS-RTK. A final total of five GCPs via DGPS-RTK and 35 target points were measured by the total station. The target points were all transformed to WGS84 with 3D accuracies of 21.2 and $26.8 \mathrm{~mm}$ in the horizontal and vertical directions, respectively, after triangulation net adjustment. With the target points, we combined and registered the point clouds of the cliff terrain via Riegl and those of the building via Faro Focus 3D.

(2) Data acquisition of multiple laser scanner integration

Three types of laser scanners with different distance ranges (i.e., $1200 \mathrm{~m}$ with Riegl VZ 1000, $120 \mathrm{~m}$ with Faro Focus 3D, and $0.5 \mathrm{~m}$ with Handyscan) were adopted for the 3D data acquisition in 
difficult environmental conditions. Equipment choices, logistics, scanning stations, and environmental conditions must be considered in survey planning to ensure the quality of 3D data. The whole survey plan included three steps, and the complete data acquisition took 11 days of field work.

In the first step, the long-distance laser scanner with Riegl VZ 1000 was positioned on the three sites opposite Liangyi Temple, as shown in Figure 5. These sites have a platform and pedestrian steps that link to the Temple. The distance between the platform and Liangyi Temple is less than $1000 \mathrm{~m}$. In each station, high-density scanning with the highest angle resolution of $0.0024^{\circ}$ in both vertical and horizontal scan lines was taken first in the specific sight view angle to Liangyi Temple. Then, the fine and detailed scanning of the target point was taken point by point after the targets were recognized automatically with RiSCAN PRO software. Riegl VZ 1000 is composed of a high-performance long-range laser scanner with a wide field of view and a calibrated digital camera firmly mounted on the scanning head of the laser scanner. After 3D point cloud data acquisition, the system then took images with the top-mounted camera in certain positions to obtain colorful visual information of the cliff and building surface, as presented in Figure 5b. Each station took one day of field work, including $3 \mathrm{~h}$ for density scanning, 1 hour for target fine scanning, and 3 min for image capture. Scanning from the three stations finally acquired the 3D data of the cliff terrain and the whole building with ground sampled distances of $2 \mathrm{~cm}$, as shown in Figure 5c.

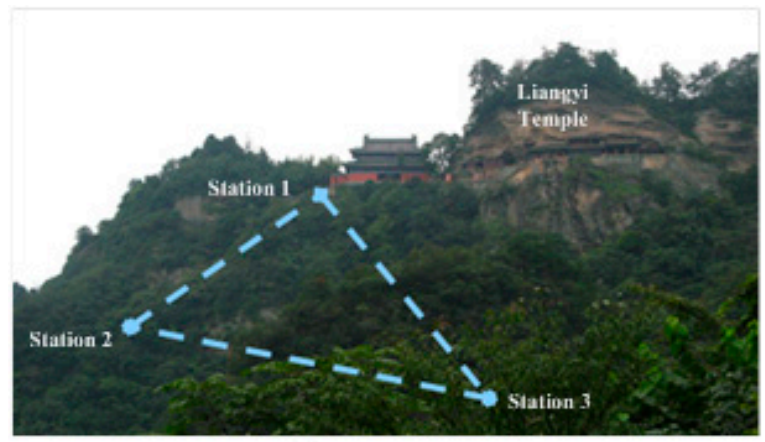
(a)

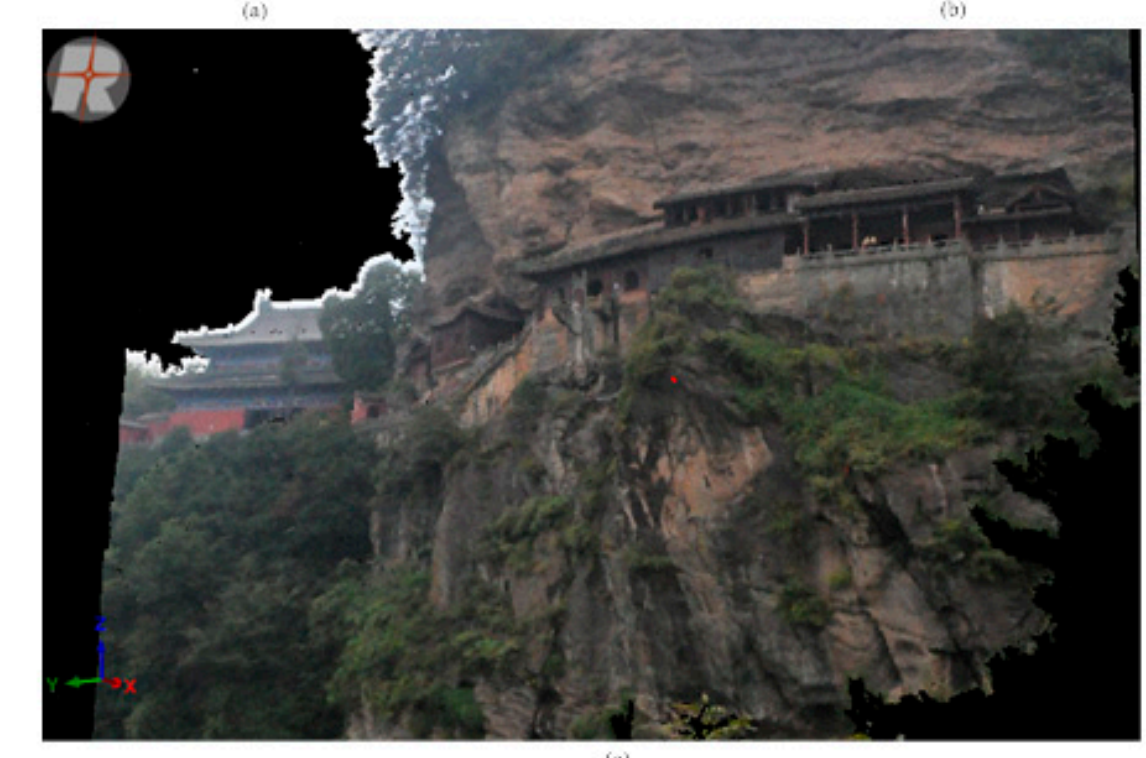

(c)

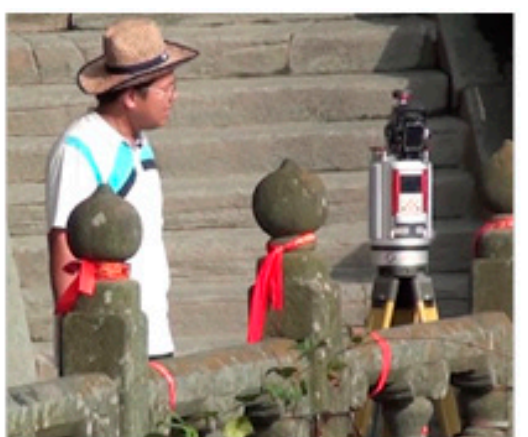

(b)

Figure 5. Long-distance laser scanner was used to acquire 3D data of the cliff terrain, and the scanning stations were located throughout the whole building (a); (b) scanning work scene on the platform; (c) 3D point cloud data with color information.

In the second step, the middle-distance laser scanner with Faro Focus 3D was presented to collect 3D data of the building body in detail. The building was divided into five parts, namely, gate, 
corridor, attic, stair, and roof, and scanned from 53 positions (Figure 6) during five days of field work. Each position had more than five reference sphere targets, and no less than three targets that should be scanned in the neighboring position. For the narrow space, where the positions between stair and roof lacked target points, some feature points in the point cloud of the long-distance scanner with Riegl VZ1000 were used as target points for data registration. All these positions also collected $360^{\circ}$ panoramic images with the built-in camera to obtain the visible information.

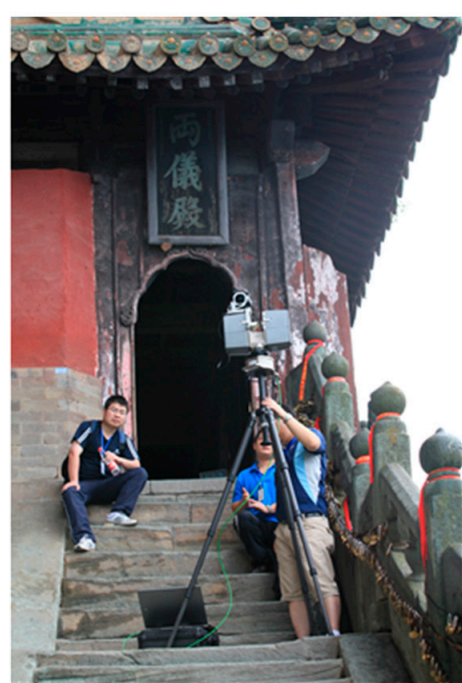

(a)

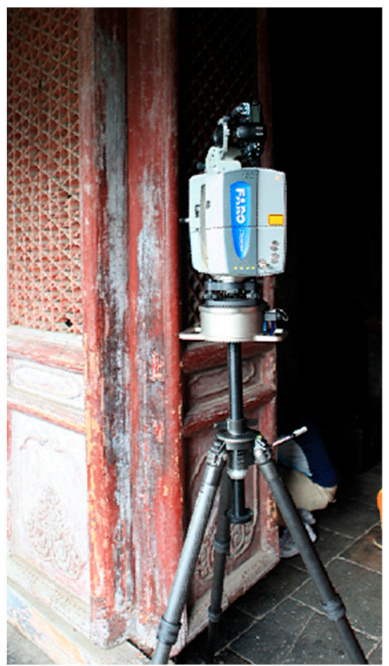

(b)

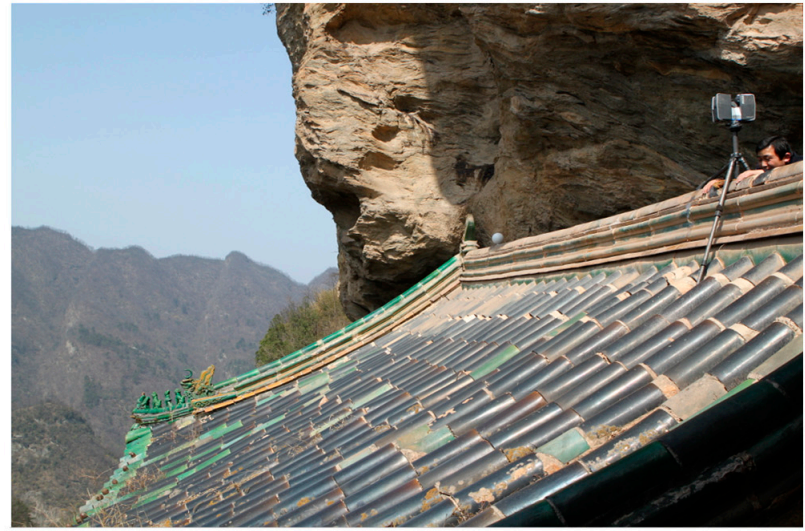

(d)

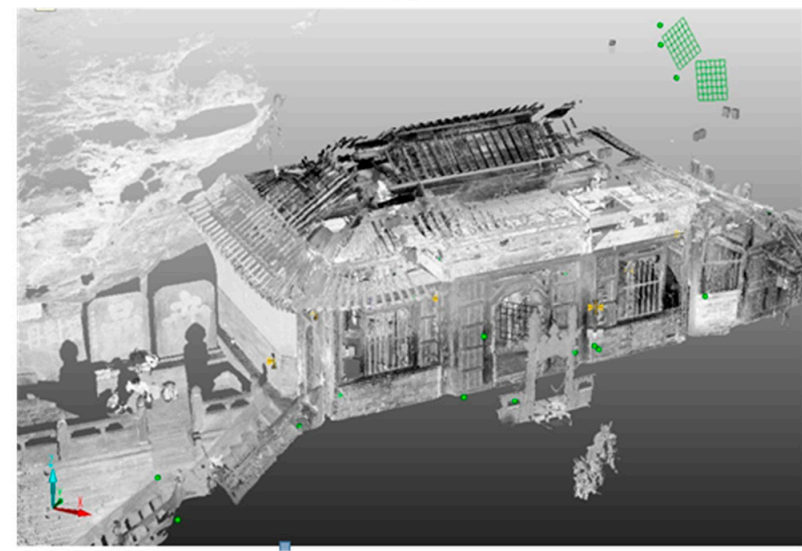

(f)

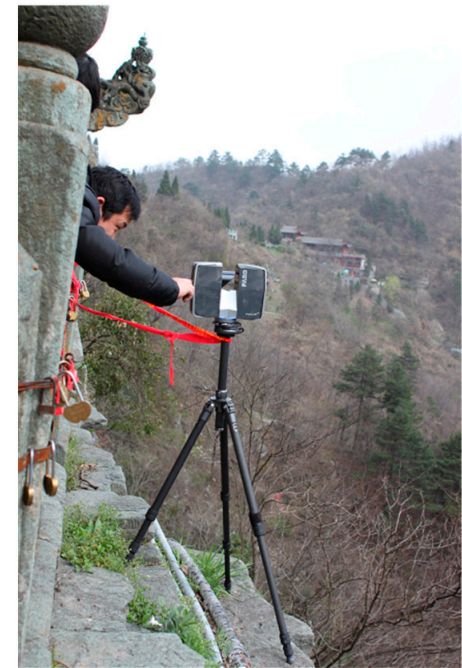

(c)

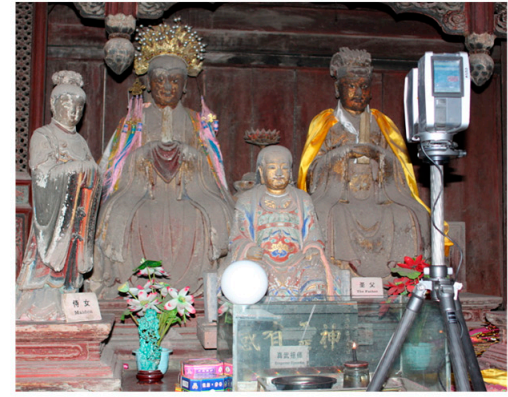

(e)

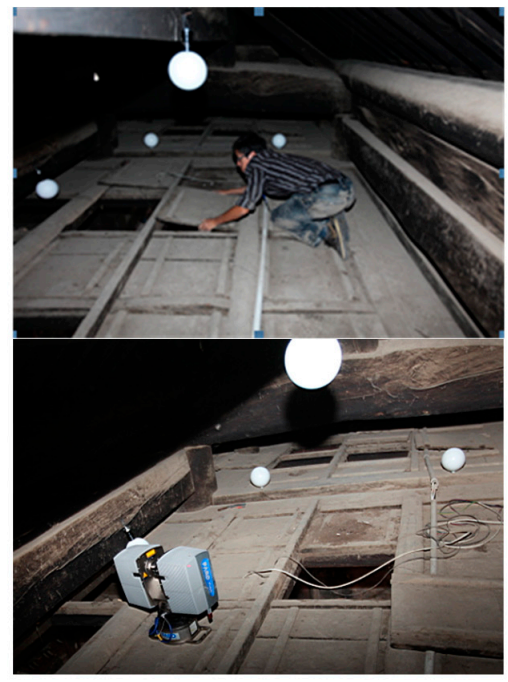

(g)

Figure 6. 3D data collection for the building. (a) Scanning for the gate; (b) scanning for the corridor; (c) scanning for the Longtou Incense; (d) scanning for the roof; (e) scanning for the statues; (f) point cloud of the whole building; (g) scanning for the attic. 
In the last phase, the handheld laser scanner with Handyscan was adopted to acquire 3D data of some important components of the building, such as Longtou Incense, status, decoration of the building, horned beast, and Vatan on the roof (shown in Figure 7). The windows with special engraving were also documented with the handheld scanner. In this phase, another two days of field work were taken to collect 3D data of some concealed regions in the corner and some missed important components after we merged all the data of the previous steps and checked the data quality.

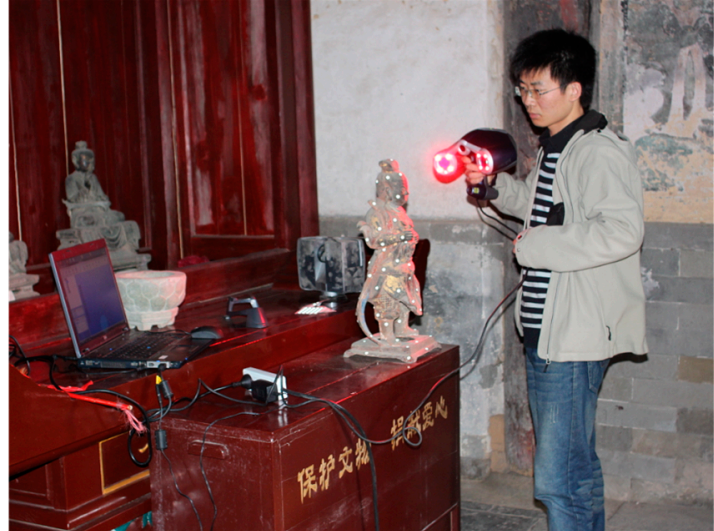

(a)

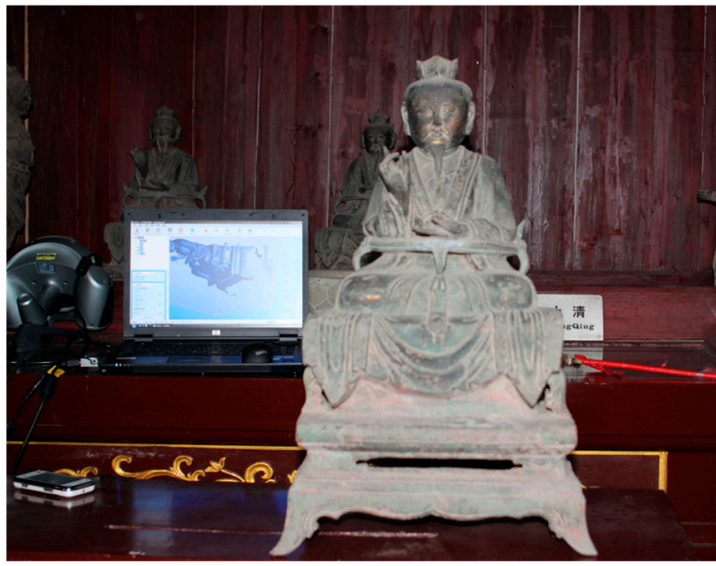

(c)

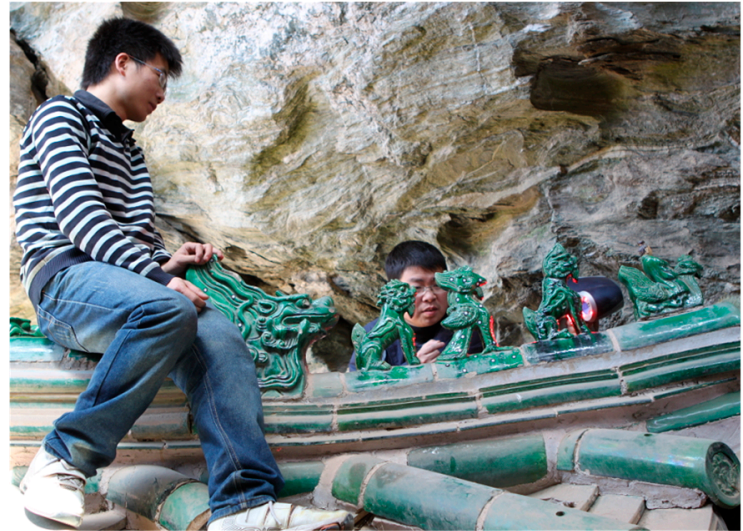

(b)

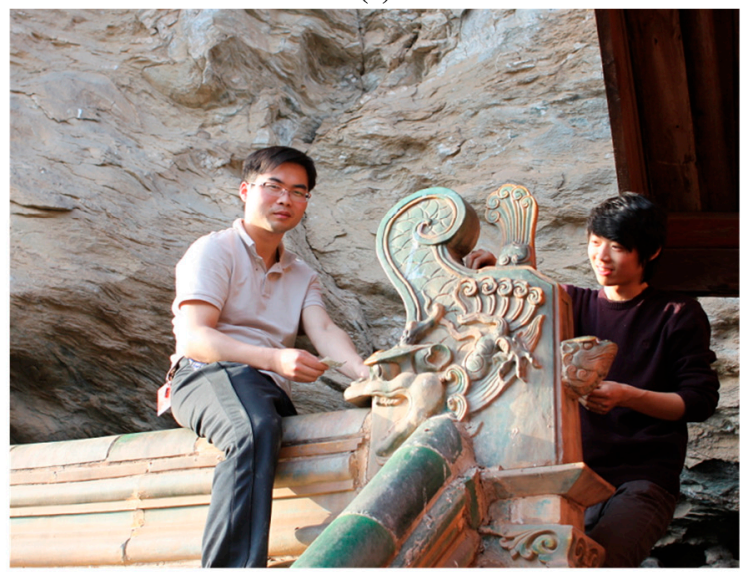

(d)

Figure 7. 3D data collection for some components with the handheld scanner. (a) Small statue scanning; (b) rows of horned beast scanning; (c) large statue scanning; (d) corner horned beast scanning.

Although the whole area of Liangyi Temple is very small, less than $50 \mathrm{~m}^{2}, 11$ days of field work was spent for 3D data acquisition with the three-level laser scanner. The total data volume was approximately $2 \mathrm{~TB}$, including 83 positions of point cloud, 53 panoramic images with a resolution of $1 \mathrm{~cm}$, and 11 high-resolution images with a resolution of $5 \mathrm{~mm}$.

\subsection{D Data Registration and Preprocessing}

The 3D data obtained from different laser scanners focused on different parts of Liangyi Temple. In accordance with our data collection plan, a combined registration approach based on different models in different software was presented for the 3D data registration, as shown in Figure 8. The foundation of 3D data registration is a unique WGS84 coordinate system. For the three-position dataset via Rigel VZ1000, we used RiSCAN PRO software for data registration. After directly adding WGS84 coordinates of the target points, all the points from three positions could be registered and geo-referenced in the WGS84 coordinate system. The 3D data registration of the building acquired with Faro Focus 3D included two steps. In the first step, 53 position data were registered through the reference sphere target points as indicated in the flowchart provided by Faro Scene software via 
an independent relative coordinate system. In the second step, the whole dataset was registered by the extracted target points for geo-referencing in the WGS 84 coordinate system. A surface-based registration method developed by the chair of Photogrammetry and Remote Sensing at ETH Zurich, called least squares 3D surface matching [35], was applied to register the 3D data of the scattered point cloud datasets from Handyscan by integrating the point cloud dataset of the components and the building with a strict geometric constraint. After performing all the registration processes, the absolute reference system for the 3D data was WGS84.

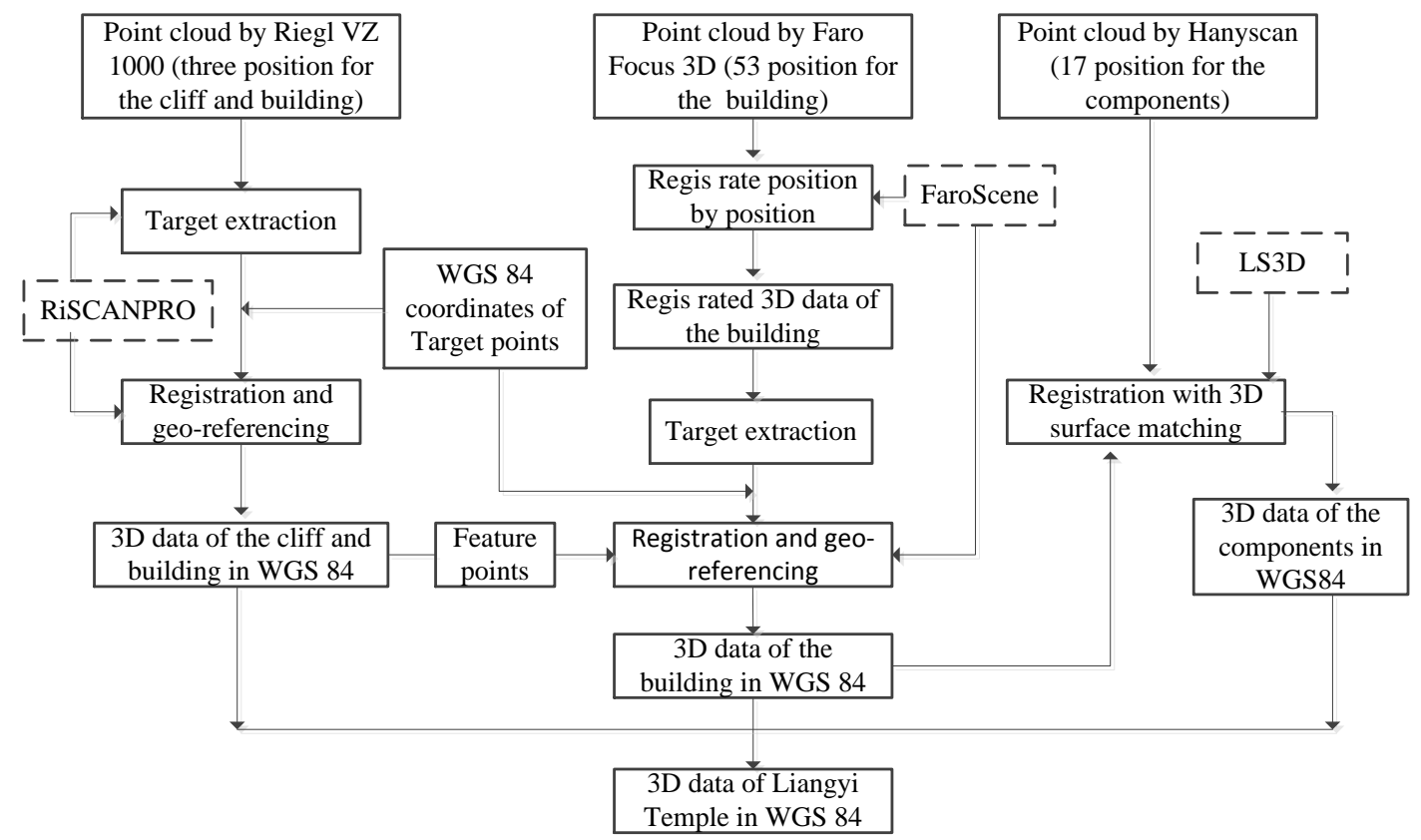

Figure 8. 3D Data registration approach for the point cloud of a different scanner.

A globally registered point cloud with high accuracy was generated through the proposed 3D data registration approach for further processing and application. Before the data processing for the fine map drawing and modeling, some data preprocesses were presented to remove the moving objects in the point cloud dataset and filter out the noise points. The preprocessing of moving object removal was implemented with Terrosolid software both semi-automatically and manually. For the point cloud of the components, both noise points and data holes exist, as revealed in Figure 9a,c. Geomagic Studio software was introduced for noise filtering and hole repair to achieve a high-quality point cloud dataset. Figure 9d,e show the result of one component dataset after filtering and repair.

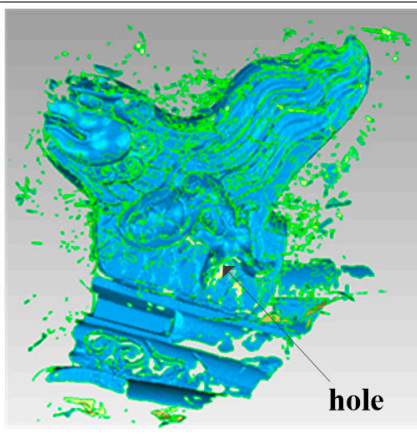

(a)
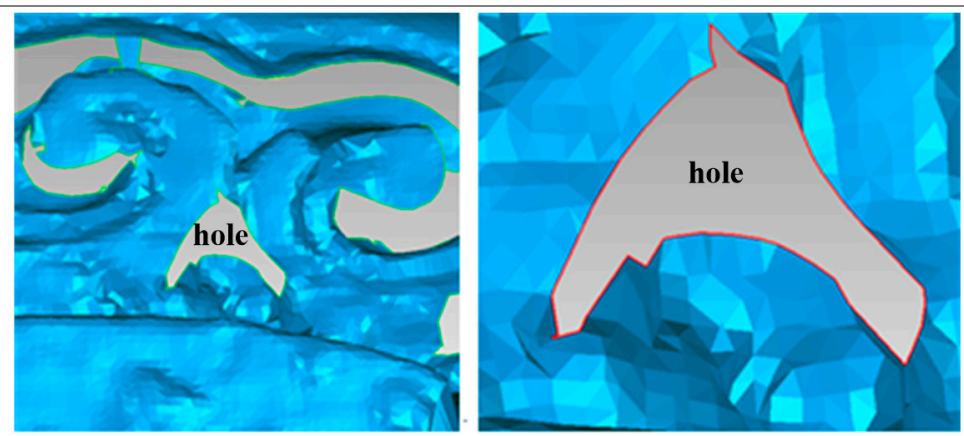

(b)

Figure 9. Cont. 


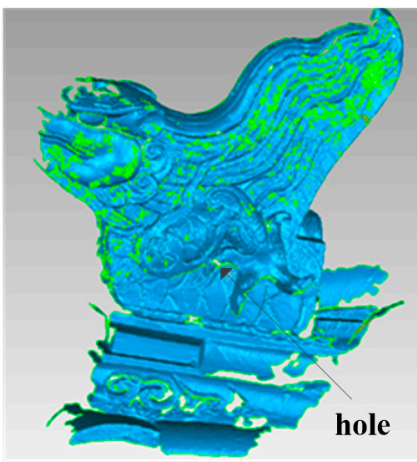

(c)

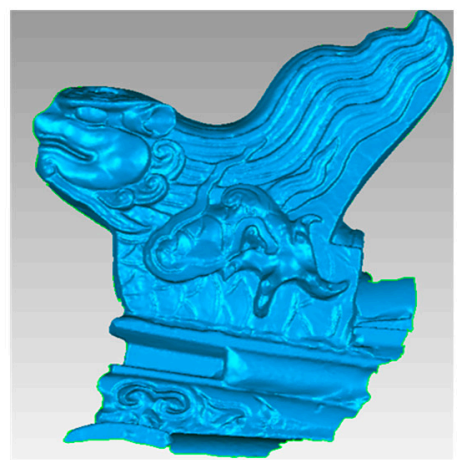

(d)

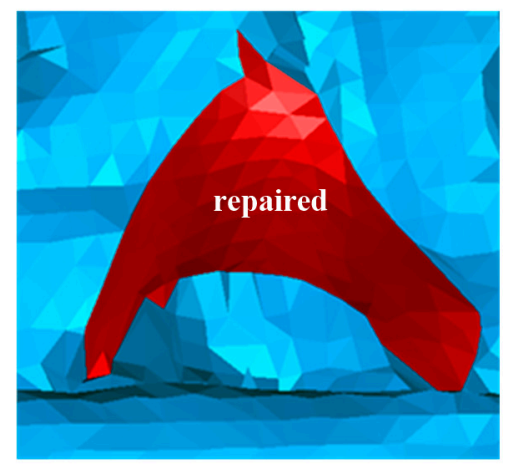

(e)

Figure 9. Noise filtering and data repair of the component point cloud: (a) original point cloud; (b) hole in detail; (c) result of noise filtering; (d) result after filtering and repairing; (e) result of data repair.

\subsection{Data Processing: Point Cloud Projection and Slicing}

The 3D data processing aims to achieve fine map drawing and 3D modeling with the registered point cloud. The complex architecture is composed of various geometric objects and is represented by three-view drawings in different planes. The main work of fine surveying aims to generate all types of three-view drawings and plane drawings of the geometric components of the building for use in 3D modeling of the architecture [36]. The projection and slicing of point cloud are usually adopted to simplify the data and highlight the geometric feature by drawing all these plane maps with a large volume of point cloud. In this section, point cloud projection and point cloud slicing approaches are proposed in detail for the fine surveying of complex architecture.

(1) Point cloud projection

The method of point cloud projection was first suggested for automatic building model reconstruction. Projection simulates the intuitive data handling of a user who tries to recognize the structure of a 3D point cloud by rotating it into specific projections $[37,38]$. In the specific projection, the geometric aspect, such as the building layout, can be formalized and structured. The projection can also simplify 3D data into the 2D place with minimal data volume. The fine drawing of Liangyi Temple benefits from point cloud projection because the arbitrary view can be defined with the drawing of a user. AutoCAD 2011 can support point cloud data. The point cloud data should be converted in the specific format of *. pcg to obtain a high-efficiency index before importing the point cloud data into AutoCAD 2011 software. Once the point cloud data are loaded via AutoCAD 2011, the point cloud can easily be handled with a user-defined projection. Figure 10 shows some typical point cloud projections of the building. The point cloud projection converts 3D data into 2D space. In the 2D space, the point cloud can be rendered as a gray image (as Figure 10a), in which the gray value is mapped as the linear model based on the distance from the point to the projection plane. All the three-view drawings of the building can be generated with point cloud projection. The vertical projection is used for the layout map. The side view projection can generate the gate map, while the front view projection is used for the face map of the building.

(2) Point cloud slicing

The slicing method for mass 3D point data to construct a CAD model is commonly used in reverse engineering technology. Slicing data are automatically or manually grouped from the 3D point dataset according to the single principle feature to recognize the border, which is useful for surface modeling of complex objects [39,40]. The slicing method of point cloud always combines with the projection approach, as shown in Figure 11. First, the cloud data are segmented into several layers by slicing the point cloud along a user-specified direction. Next, the sliced data points in each layer are projected onto an appropriate plane and then used to reconstruct geometric objects. 


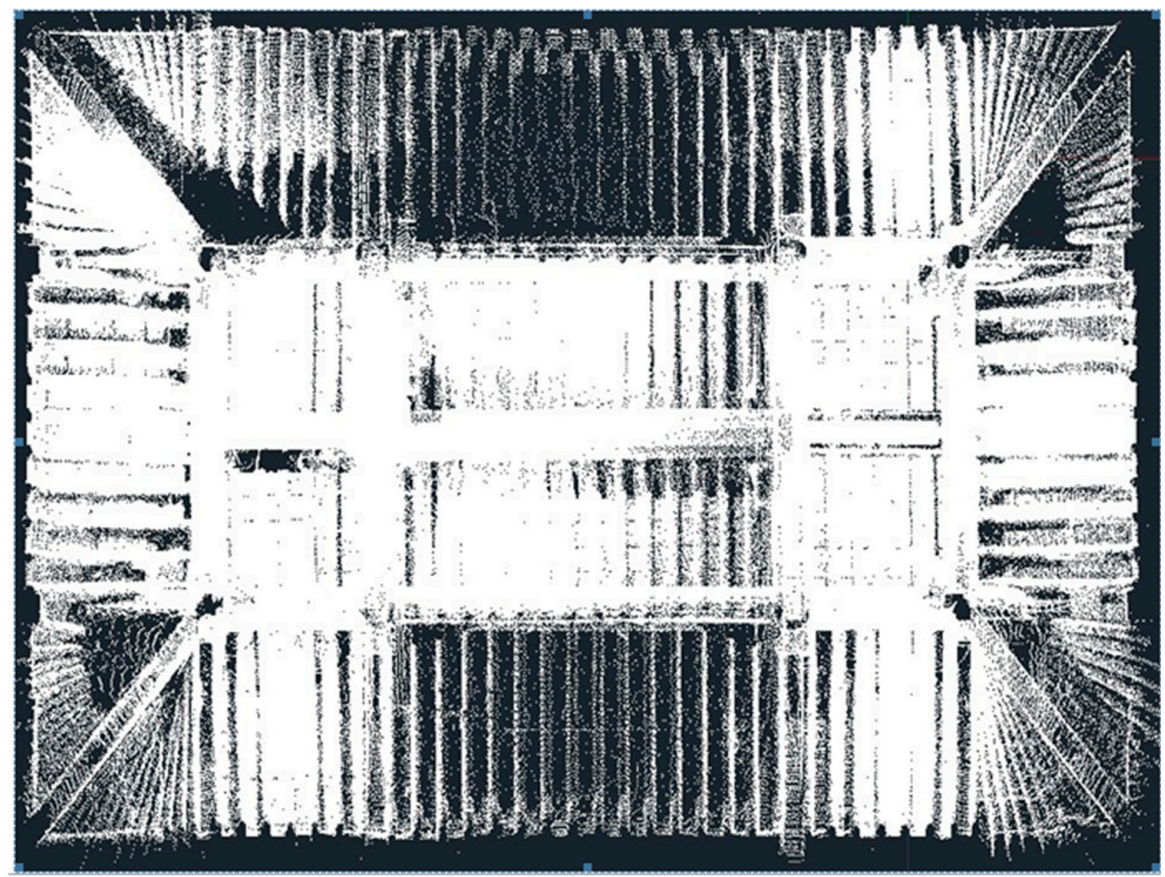

(a)

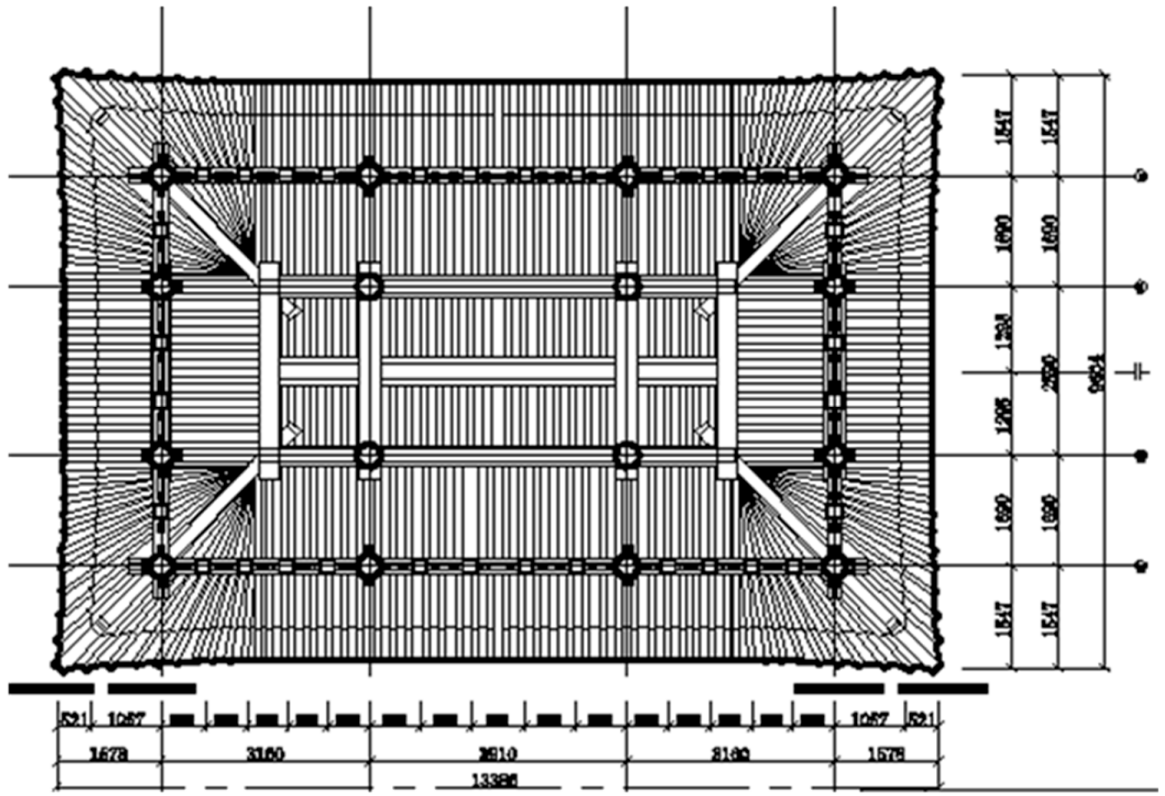

(b)

Figure 10. Point cloud projection for the plane drawing of the building roof. (a) Point cloud projection; (b) plane drawing based on point cloud projection.

The most important work for point cloud slicing is to determine the layer thickness, which is sensitive to accuracy and shape extraction. A small layer thickness leads to missed shape features, whereas a large layer thickness causes the shape feature to submerge in the heavy point cloud data. Thus, layer thickness should be defined as a different type of architectural component. The point cloud slicing function is provided by Kubit software from Faro Company. Kubit is a point cloud processing software that combines sophisticated measuring technologies with the established CAD-functionality seamless integration into AutoCAD for surveying, construction, and architecture. Kubit plug-in support can be used to define an arbitrary direction and layer with a specific thickness, and thus obtain the slicing data for the fine drawing of component. Figure 12 illustrates the fine surveying and 
drawing results of some typical components, such as ridge tie beam, crescent beam, hip rafter, and architrave, through the point cloud slicing method.

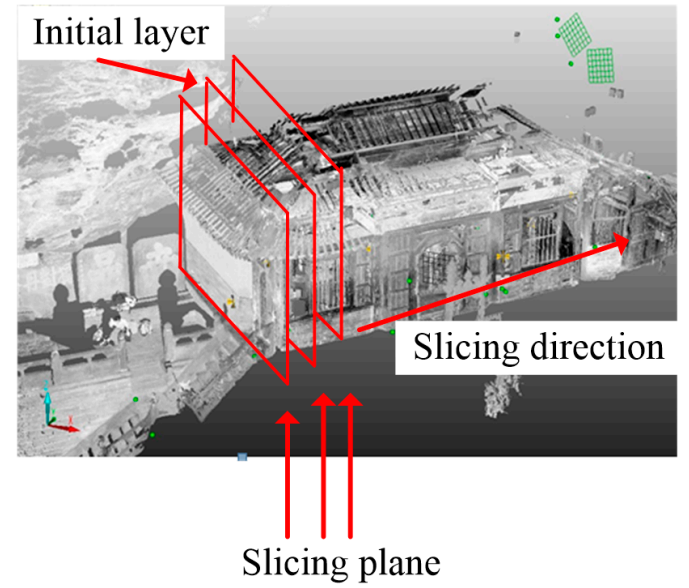

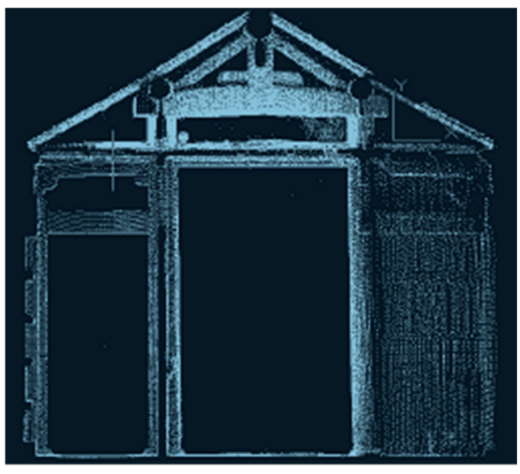

The projected points of initial layer onto the projected plane

Figure 11. Point cloud slicing and projection.

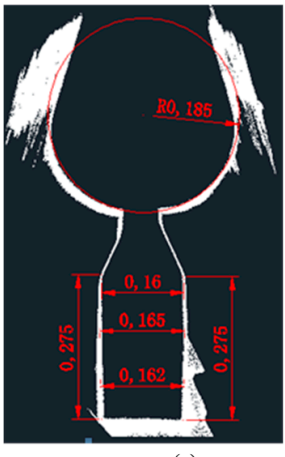

(a)

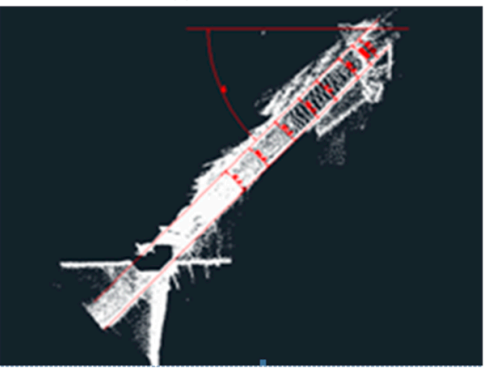

(c)

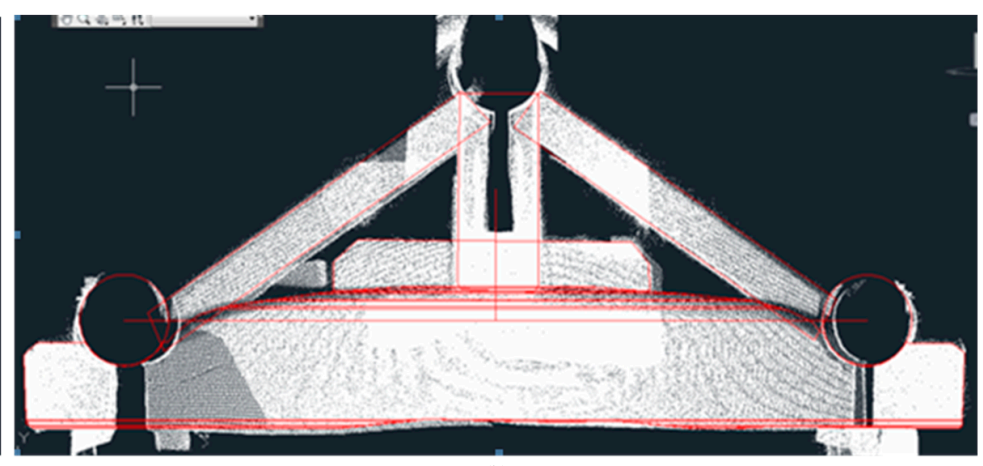

(b)

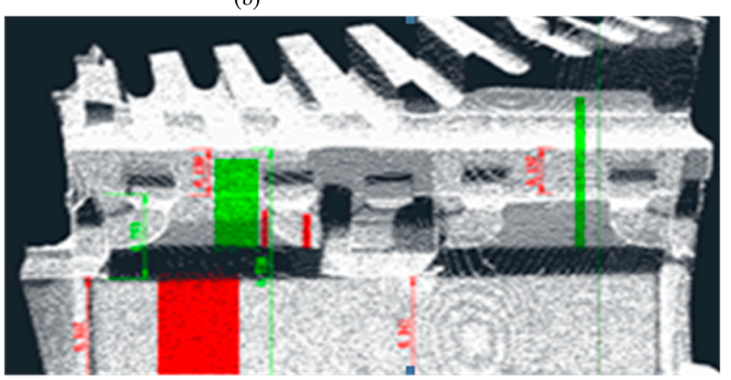

(d)

Figure 12. Fine drawings of typical components: (a) ridge tie beam; (b) crescent beam; (c) hip rafter; (d) architrave.

\subsection{D Modeling}

The 3D modeling of architecture has two levels. One is reality-based 3D modeling, and the other is reconstructive 3D modeling [41]. Reality-based modeling uses registered point clouds to generate high-resolution polygons based on 3D triangulation, called a polygonal model. The polygonal model can be directly rendered as a 3D scene, which can also map the image as visible information. Reality-based modeling presents several topological errors, which are caused by residual errors that survived the cleaning phase, and a huge numbers of holes, which are related to the shadow effects of the complex geometry. A limitation exists for the 3D representation of the complex architecture, particularly the internal composition [42,43]. Thus, we use reality-based modeling to represent the attached historical relics in Liangyi Temple, such as the famous Longtou Incense and Taoism statues 
shown in Figure 13. The procedure of reality-based polygon modeling and rendering is partly shown in Figure 9 together with the preprocessing for these types of components via Handyscan.
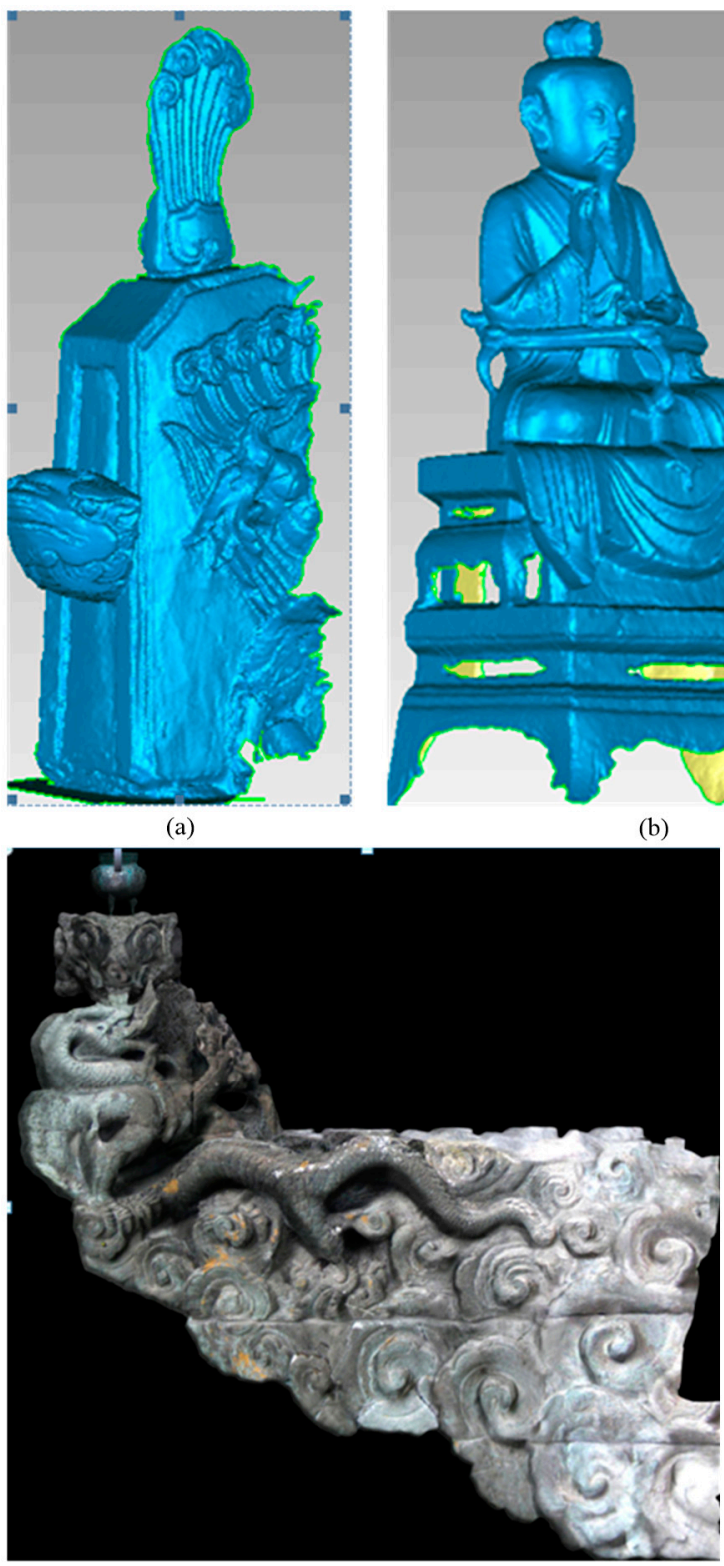

(d)

(b)
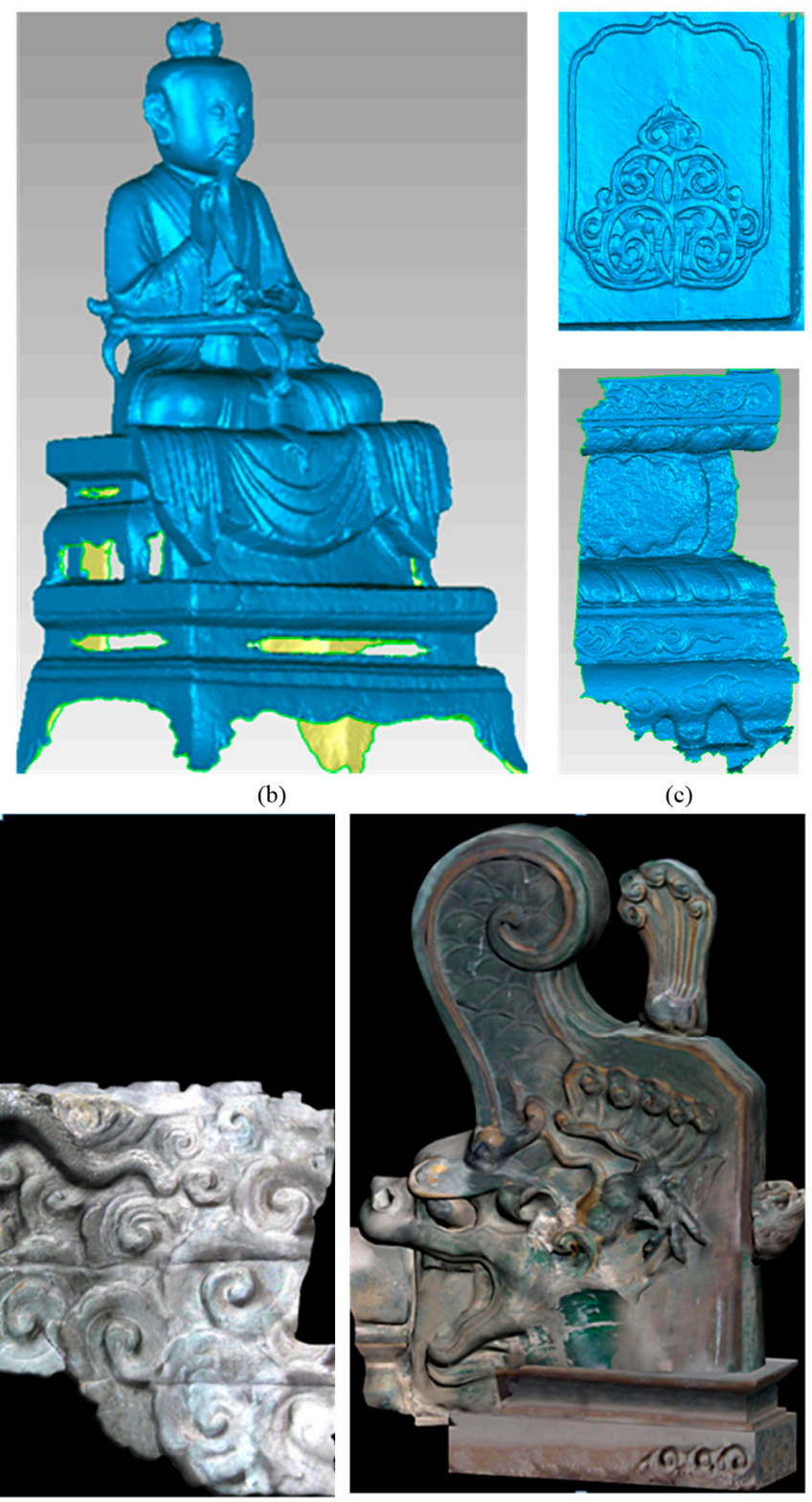

(e)

Figure 13. Reality-based 3D modeling of historical relics. (a) 3D model of horned beast; (b) 3D model of statue; (c) 3D model of sculpture; (d) texture-mapped 3D model of Longtou Incense; (e) texture-mapped 3D model of horned beast.

Compared with reality-based modeling, reconstructive 3D modeling aims to structure the architectural elements. It is also object oriented along with topological information, which can be spatially indexed for further query, highlighting, and selection. All these properties are very important for architectural management and reconstruction in the digital architecture preservation projection.

Reconstructive 3D modeling starts from the fine surveying drawings in Section 3.3, which contain the geometrical information in reality-based models of both single buildings and historical relics in the whole aligned scene. The three-view drawings, such as plan drawings, facade drawings, and section drawings, are adopted for the 3D modeling of the building in AutoCAD 2011 software, as shown in Figure 14. The accurate building footprints, height of architectural elements, and positioning of the 
relics are determined according to their actual configuration in the $3 \mathrm{D}$ reconstruction phase. The 3D models of the architectural components are also generated from their fine drawings and objective geometrical constraints in AutoCAD 2011, as presented in Figure 14e,f. Texture mapping is also implemented in AutoCAD 2011 with high-resolution images from the field data collection.

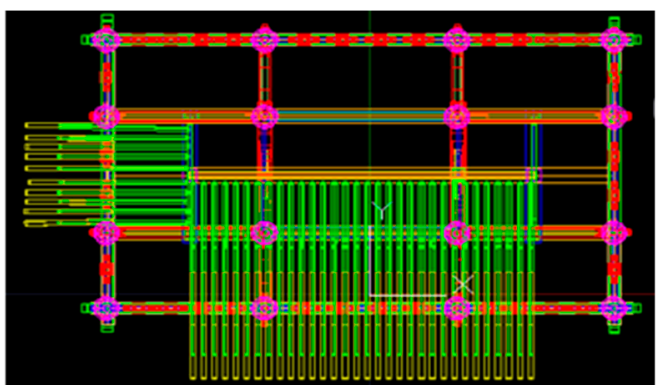

(a)

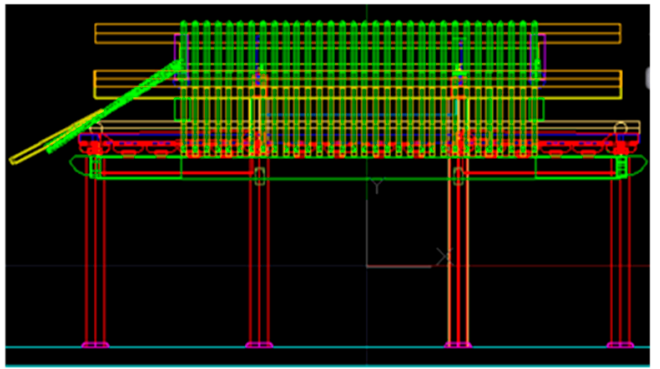

(c)

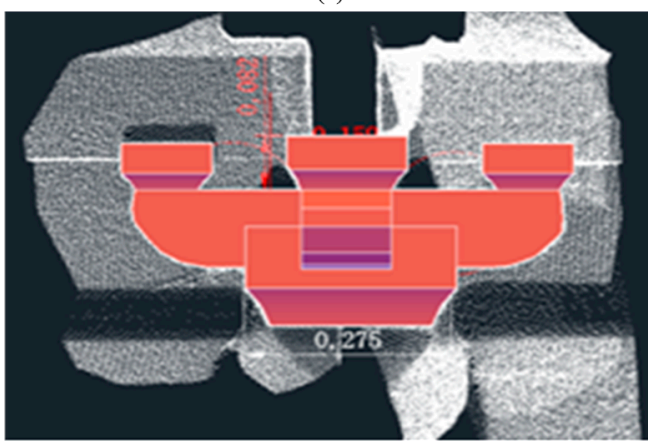

(e)

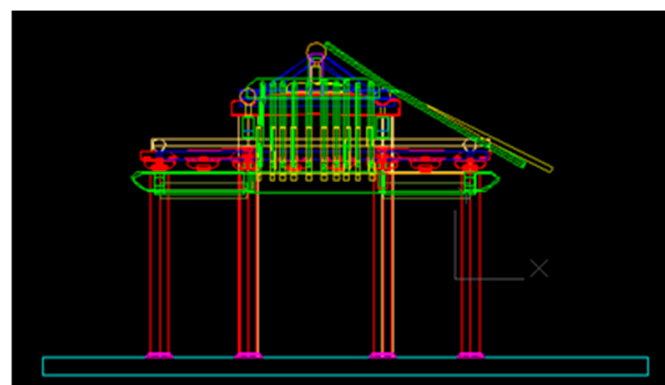

(b)

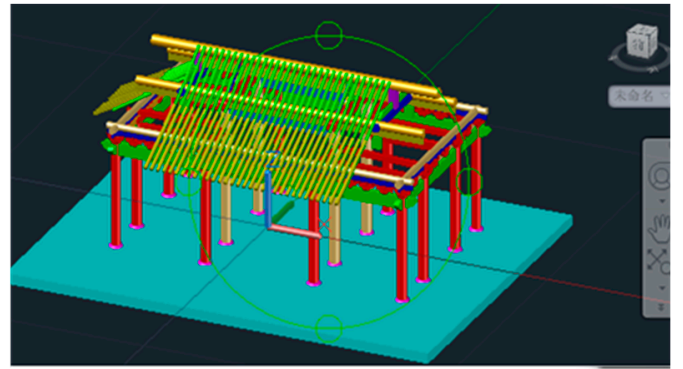

(d)

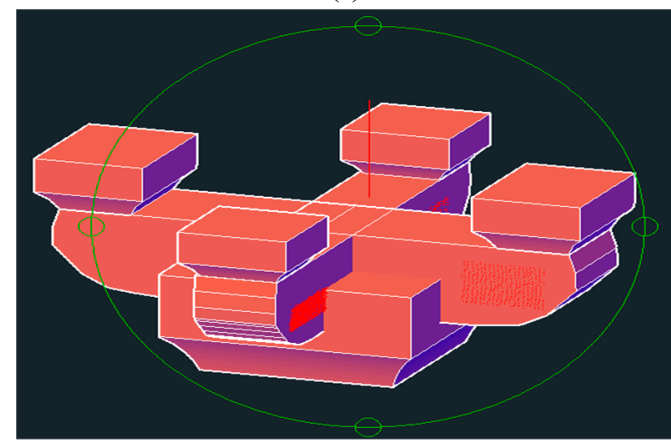

(f)

Figure 14. Reconstructive 3D modeling of the architecture. (a) Plan drawing of the building; (b) section drawing of the building; (c) facade drawing of the building; (d) reconstructive 3D model of the building; (e) architectural component modeling; (f) reconstructive 3D model of the component.

We also use the approach introduced by Gabriele to ensure the quality of 3D modeling by double checking the 3D model of the complex architecture [44]. First, the reality-based digital model is used to check the coherence of each reconstructive step. The digital reconstructed models are continuously compared with the reality-based models to verify possible incoherencies introduced during the reconstruction procedure. Second, the high-resolution images, including the 360 panoramic images from the field data collection together with the architectural archaeologist, are introduced to check the ancient architecture structure. These architectural structure checks include the architectural structure, architecture with decorations, relics in the architecture, and final texturized architecture.

\section{Results and Discussions}

\subsection{Results and Analysis}

The proposed approach aims to maintain and achieve the digital preservation of the wooden architecture of Liangyi Temple through fine surveying and 3D modeling. We introduce the final 
results, which include three parts: (1) fine drawings; (2) 3D models; and (3) deformation analysis of the architectural structure.

(1) Fine drawings of Liangyi Temple and accuracy analysis

A total of 148 drawings of Liangyi Temple are obtained from the multiple TLS integration point cloud data. The fine drawings include a series of scale maps. The details of these drawings are shown Table 1. Figure 15 shows some typical fine drawings of Liangyi Temple; these drawings are the foundation of the digital reconstruction and preservation of Liangyi Temple.

Table 1. Fine drawings of Liangyi Temple.

\begin{tabular}{ccccc}
\hline Type & Components & Description & Map Scale & Number \\
\hline Plane drawing & building & two floors & $1: 50,1: 100$ & 3 \\
Facade drawing & building & front and side views & $1: 50$ & 2 \\
Section drawing & building & cross and vertical sections & $1: 50$ & 9 \\
Detail design & bracket set & four corners & $1: 10,1: 20$ & 8 \\
Bottom view & beam & hall and corridor & $1: 50$ & 2 \\
& & entablature, column base, hip rafter, & $1: 5$ & 124 \\
Detail design & components & architrave, tile end, inverted & $1: 10$ & $1: 20$ \\
& & V-shaped brace, camel hump-shaped \\
& support, partition door & 10 & \\
\hline
\end{tabular}
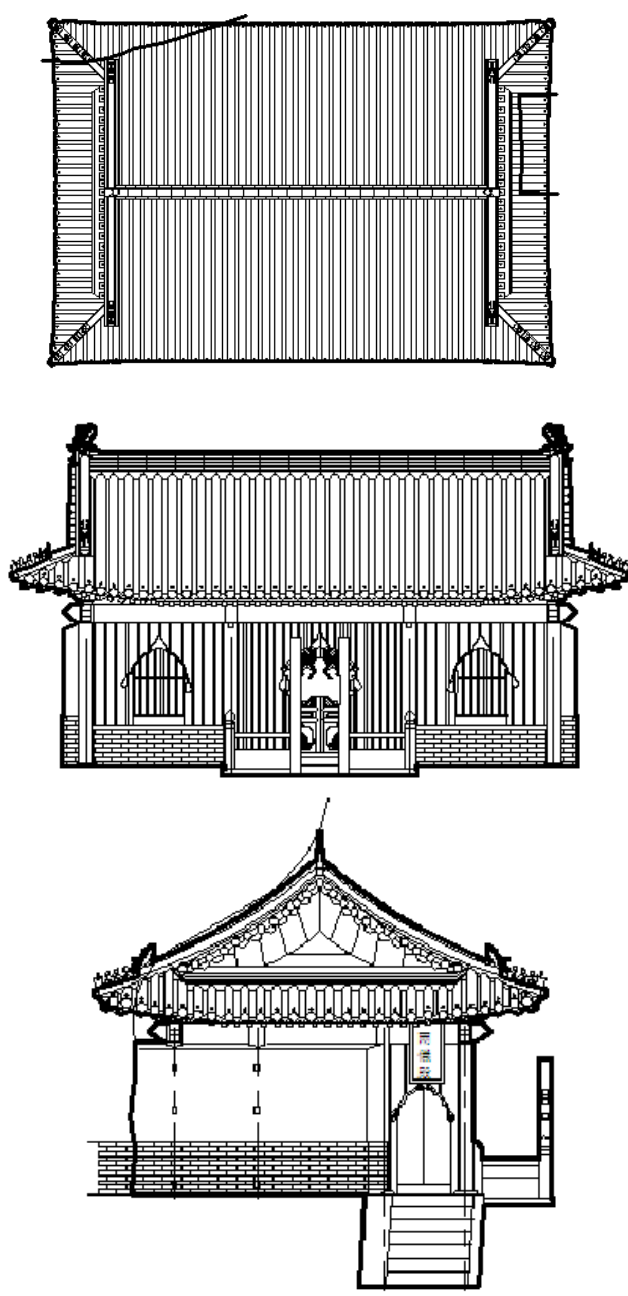

(a)
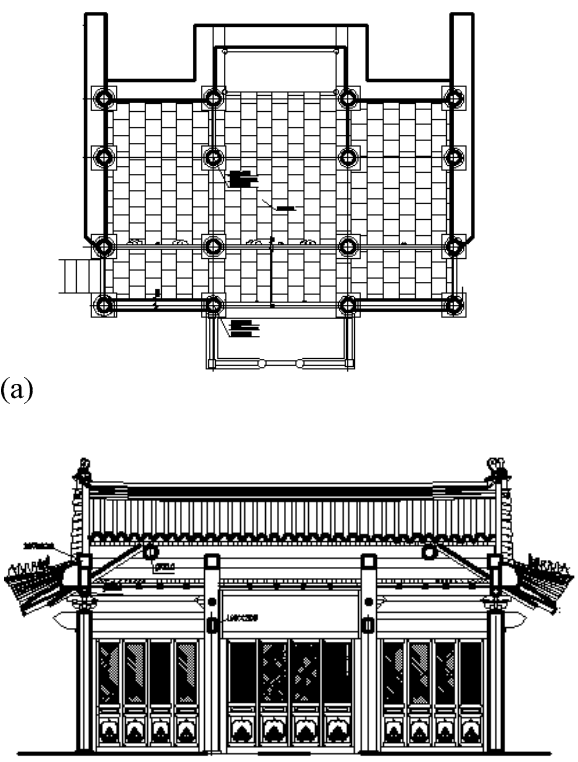

(b)

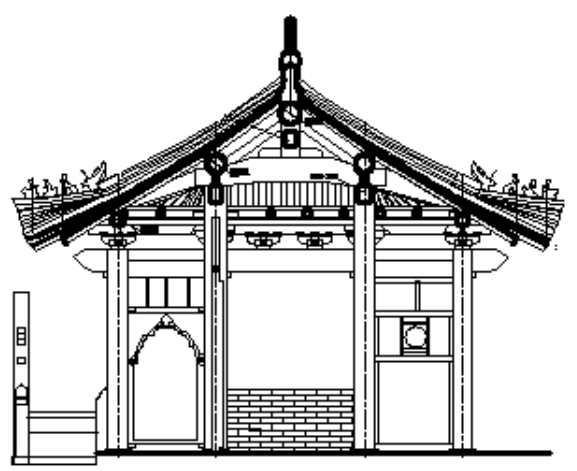

(c)

Figure 15. Cont. 


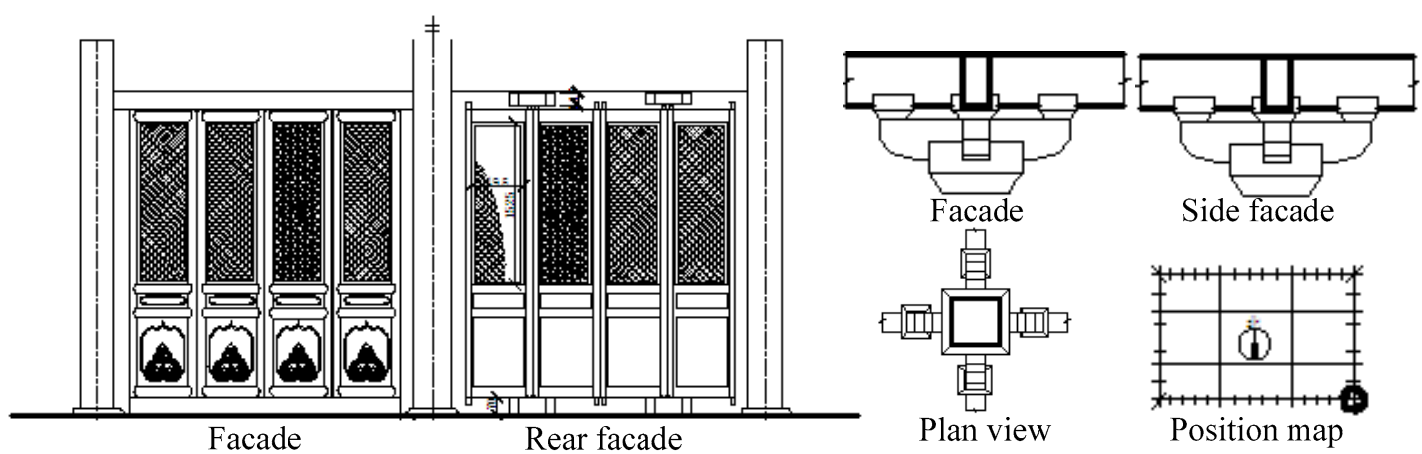

(d)

Figure 15. Fine drawings of Liangyi Temple. (a) Plane drawings (layout); (b) facade drawings; (c) section drawings; (d) window drawings and bracket set drawings.

According to the fine surveying technique requirements of the wooden architecture, each component has a large-scale drawing from the point cloud with precise geometric size. We randomly select some components of the building to evaluate the accuracy of the fine surveying results with the proposed approach in this study by measuring the geometric parameters with a ruler or a total station. These parameters were compared with the geometric size from the fine drawings. The accuracy result is reported in Table 2 .

Table 2. Accuracy of fine surveying with the proposed approach.

\begin{tabular}{|c|c|c|c|c|c|}
\hline Components & Type & View & $\begin{array}{l}\text { Measurement } \\
(\mathrm{mm})\end{array}$ & $\begin{array}{c}\text { Measurement } \\
(\mathrm{mm})\end{array}$ & Error $(\mathrm{mm})$ \\
\hline Narrow tie beam under ridged purlin & Length & Left & 122 & 119 & -3 \\
\hline wide tie beam under ridged purlin & Width & Left & 168 & 169 & 1 \\
\hline narrow tie beam under south Quan & Length & Left & 211 & 212 & 1 \\
\hline wide tie beam under south Quan & Width & Left & 76 & 78 & 2 \\
\hline narrow tie beam under north Quan & Length & Left & 205 & 204 & -1 \\
\hline wide tie beam under north Quan & Width & Left & 178 & 183 & 5 \\
\hline inverted V-shaped brace & Width & Left & 143 & 142 & -1 \\
\hline inverted V-shaped brace & Thickness & Plane & 77 & 81 & 4 \\
\hline bracing of crescent beam & Length & Plane & 301 & 302 & 1 \\
\hline bracing of crescent beam & Width & Plane & 256 & 258 & 2 \\
\hline bracing of hip rafter & Length & Plane & 213 & 213 & 0 \\
\hline bracing of hip rafter & Width & Plane & 275 & 274 & -1 \\
\hline door of front hall & Width & Back & 3585 & 3588 & 3 \\
\hline crossbar of front hall door & Width & Back & 113 & 111 & -2 \\
\hline main door & Width & Front & 2835 & 2838 & 3 \\
\hline right side of the second door & Width & Front & 164 & 162 & -2 \\
\hline bottom side of the second door & Height & Front & 193 & 195 & 2 \\
\hline height of the wall & Height & Back & 795 & 798 & 3 \\
\hline window & Width & Back & 2862 & 2863 & 1 \\
\hline half of window & Width & Back & 894 & 891 & -3 \\
\hline baluster & Width & Back & 1265 & 1263 & -2 \\
\hline inside baluster & Width & Back & 1078 & 1076 & -2 \\
\hline \multicolumn{5}{|c|}{ Mean square error (MSE) } & 2.3 \\
\hline
\end{tabular}

${ }^{\mathrm{a}}$ measurement result by ruler or total station $(\mathrm{mm}){ }^{\mathrm{b}}$ measurement result from point cloud.

As Table 2 indicates, the accuracy of the proposed approach reaches $2.3 \mathrm{~mm}$ in MSE, which can meet the fine surveying requirement of the ancient wooden architecture. These fine drawings can be used to reconstruct the architecture and obtain the 3D model for digital architecture documentation.

(2) 3D models of Liangyi Temple

The majority of 3D models of Liangyi Temple are 3D reconstructive-based models. After texture mapping and 3D rendering of the high-resolution images, we can obtain the true 3D representation 
and documentation of Liangyi Temple (as displayed in Figure 16). The environment of the cliff terrain is finally generated based on the reality-based scene. The 3D models of vegetation are also added to the true Digital Terrain Model (DTM) to build a panoramic view of the true surroundings on a sphere, resulting in the final reconstructive panoramic view shown in Figure 17.

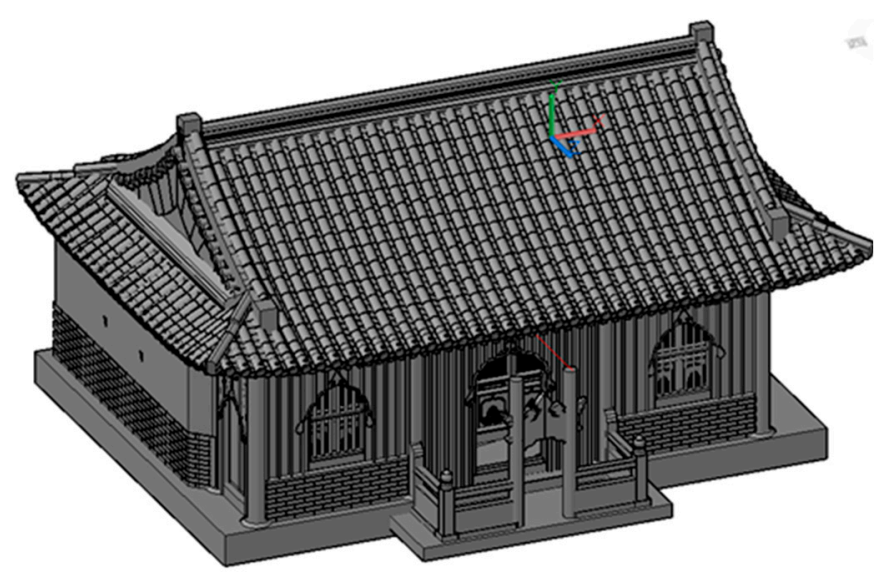

(a)

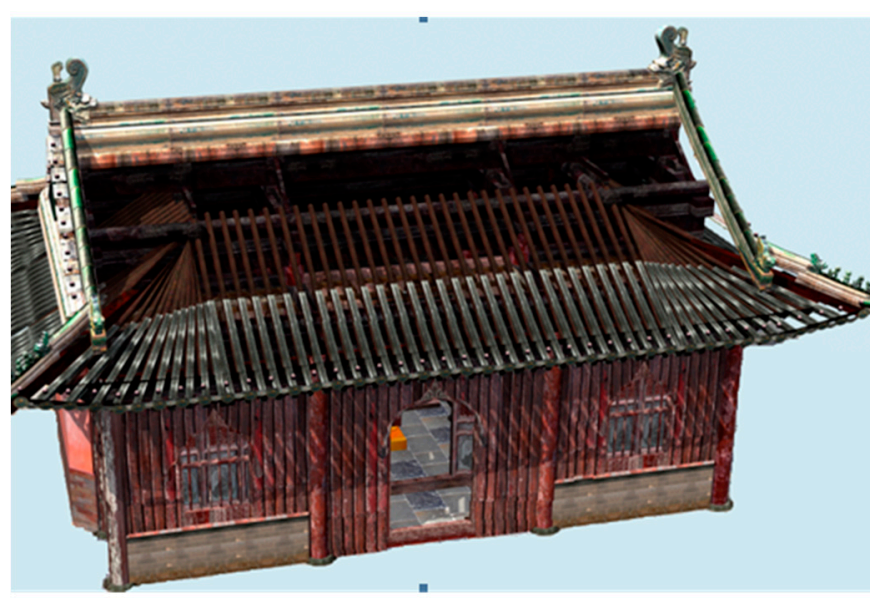

(b)

Figure 16. Reconstructive 3D model of Liangyi Temple. (a) Rendered with gray image; (b) rendered with texture mapping.

Figure 17a shows the front view of Liangyi Temple, which adds the surrounding 3D models of terrain and vegetables. Figure $17 \mathrm{~b}$ shows the top view of the entire wooden architecture. The camera viewpoint roams and turns around the temple to help obtain a bird's-eye view of Liangyi Temple. Figure 17c shows the roaming scene of the panoramic view in the reconstructed temple, in which the corridor and hall have been passed through for a detailed observation. 


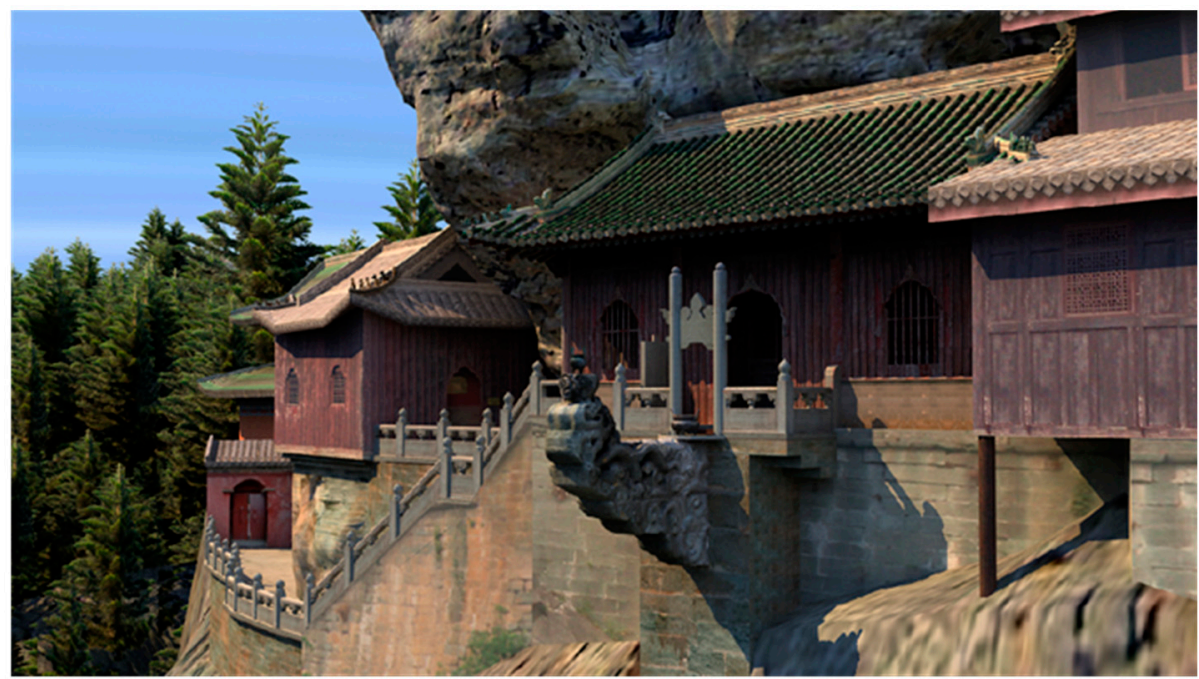

(a)

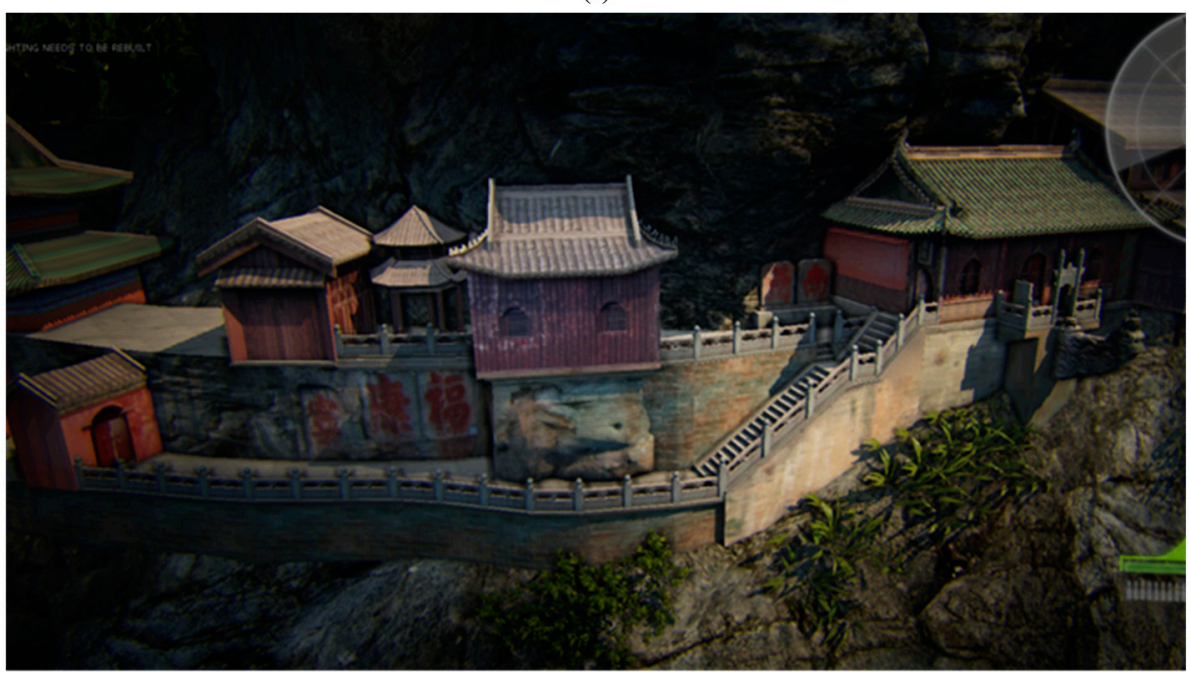

(b)
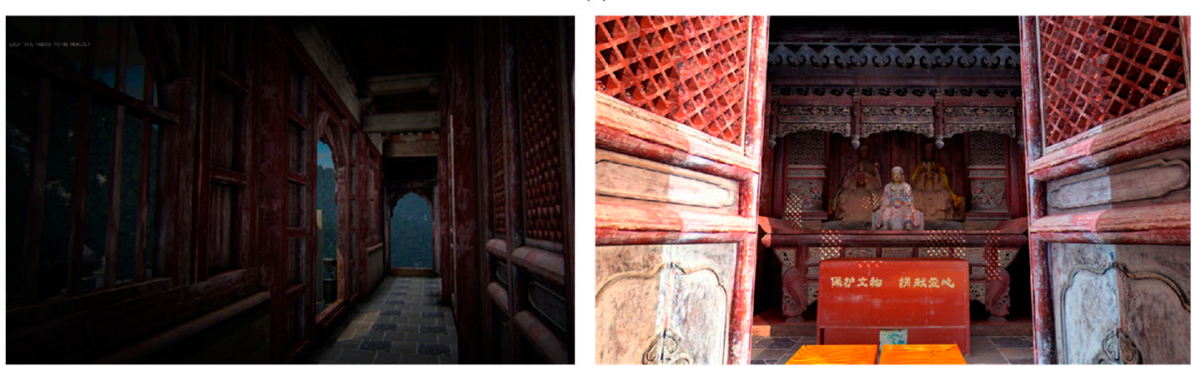

(c)

Figure 17. 3D scene of Liangyi Temple. (a) Front panoramic view; (b) top view; (c) inner view: corridor and hall.

(3) Deformation analysis of the architectural structure

The fine surveying of Liangyi Temple has another important goal, which is to determine and measure structural deformation for further monitoring and preservation projects. The proposed multiple TLS integration approach provides a well-registered global point cloud that can be used for the deformation analysis. We can obtain the slicing section in the column bases where structural deformation tends to occur through the slicing and projection method of the point cloud. Figure 18 shows one section of the building. The crooked column base is illustrated in the drawings of this section (Figure 18a). 
Figure 18 shows that the wooden column base is sloped at the top, which may be caused by the extrusion of the cliff. The crooked column can be observed clearly from the section point cloud by slicing. The section drawing is measured from the sliced point cloud. The maximized crooked gap of the column base at the top is $102.1 \mathrm{~mm}$. This gap is a very large displacement between the roof and the building foundation and threatens the integrity of the entire architecture. The deformation analysis results are given to the Heritage Management Department of Wudang Mountains for further maintenance and monitoring.

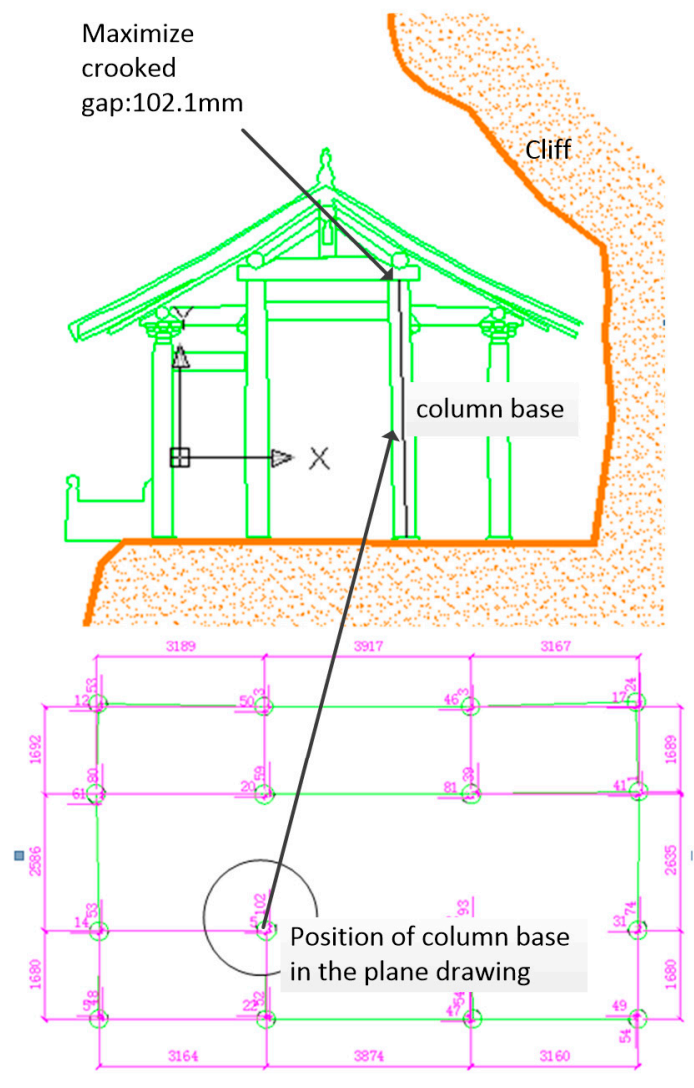

(a)

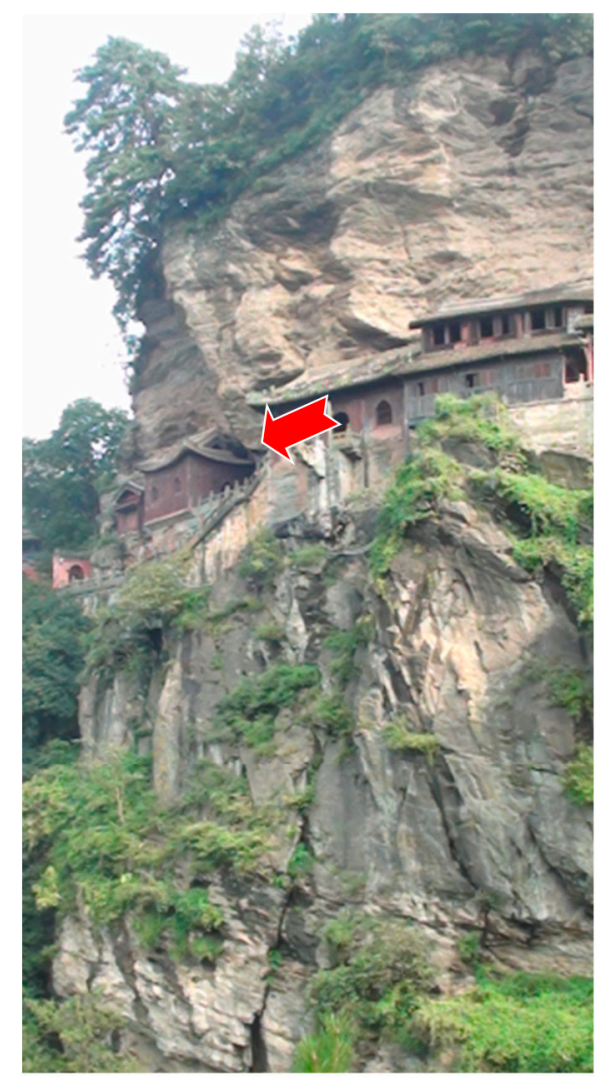

(b)

Figure 18. Deformation analysis of the column base. (a) Crooked column on the section drawing; (b) crooked direction of Liangyi Temple.

\subsection{Discussions}

As previously stated, our proposed approach aims to use multiple level terrestrial laser scanner integration for the fine surveying and 3D modeling of complex architecture in a steep and difficult environment. Although the proposed approach attempts to make up for the restrictions of mutual sheltering and reduce missed corner data, some objects in the multiple cross parts remain; these objects cannot be determined by the geometric relationship among the neighboring objects. The complex structure of the architecture with complicated elements requires both architectural knowledge and archaeological experience for the fine surveying and 3D modeling with the proposed slicing and projection method of 3D point clouds. In the 3D modeling with the point cloud and fine drawings, architectural and archaeological knowledge is also very important to the quality and accuracy of the 3D model of the architecture. All these factors are important for the reconstruction and preservation of the architecture. Hence, technical scientists and archaeologists should work together in laser scanning to conduct interdisciplinary research for digital ancient architecture projects [45].

The specific location terrain and climate environment of Liangyi Temple threaten the survival of this wooden architecture. Although we present a deformation analysis method based on the 3D point 
cloud, many destructive insect pests, such as the aforementioned white ants that often appear in this district, threaten the wooden components. The white ants can hurt the wooden component from the inside, which is the main factor behind the crooked column bases. Laser scanning can only measure the geometric deformation of the architectural structure. Microwave and X-ray technology together with high-density geometric shape measurement approaches via laser scanning have great potential in this field [46-48].

\section{Conclusions}

The work presented in this study is intended to be a valuable aid for the digital reconstruction, visualization, and preservation of ancient wooden architecture. A multiple level terrestrial laser scanning integration approach is proposed for complex architecture in steep terrain surroundings. The data processing approach with point cloud from a three-level terrestrial laser scanner is proven to be effective for fine surveying and 3D modeling. Liangyi Temple in the Wudang Tourism architecture complex is taken as a typical wooden ancient architecture to realize fine surveying and 3D documentation via the proposed approach. A total of 148 drawings of the architecture and 3D models with high-resolution texture are obtained. All these results are useful for the digital reconstruction, visualization, and preservation of the architecture. We also find a structural deformation in Liangyi Temple, which should be a subject of long-term monitoring for architectural heritage, having more than 600 years of history, in further preservation and maintenance projects. Along with future development, combining microwave and laser scanning technology for full 3D modeling of the wooden components is significant for both the surface shape and the inside structure, such as the hole infected by insect pests.

Acknowledgments: The authors would like to thank "The Compass Plan" supported by State Administration of Cultural Heritage. This research is also supported by National Natural Science Foundation of China (Grand No: 41271452) and Key Technologies R\&D Program of China (Grand No. 2015BAK03B04).

Author Contributions: Qingwu $\mathrm{Hu}$ and Shaohua Wang conceived the study and wrote the paper; Caiwu Fu conceived the study; Mingyao Ai did the field data collection and data processing; Dengbo Yu and Wende Wang implemented 3D modeling and accuracy analysis.

Conflicts of Interest: The authors declare no conflict of interest.

\section{References}

1. Zhang, Q. A Scientific approach to the origins of Chinese civilization. In An Introduction to Chinese History and Culture; Springer: Berlin, Germany, 2015; pp. 1-21.

2. Wibowo, A.S. Conservation of wooden architecture: Willingness, support and tradition. Procedia Soc. Behav. Sci. 2015, 184, 388-393. [CrossRef]

3. Rujivacharakul, V.; Hahn, H.H.; Oshima, K.T.; Christensen, P. Architecturalized. Asia: Mapping a Continent through History; Hong Kong University Press: Hong Kong, China, 2013.

4. Choi, J.; Kim, Y.; Kang, J.; Choi, Y. Comparative analysis of the spatial structure of apartment unit plans in Asia-apartments in Korea, Vietnam, and Kazakhstan. J. Asian Archit. Build. Eng. 2014, 13, 563-569. [CrossRef]

5. Chun, Q.; Van Balen, K.; Pan, J.; Sun, L. Structural performance and repair methodology of the Wenxing lounge bridge in China. Int. J. Archit. Herit. 2015, 9, 730-743. [CrossRef]

6. Mazzeo, R.; Cam, D.; Chiavari, G.; Fabbri, D.; Ling, H.; Prati, S. Analytical study of traditional decorative materials and techniques used in Ming Dynasty wooden architecture. The case of the Drum Tower in Xi'an, PR of China. J. Cult. Herit. 2004, 5, 273-283. [CrossRef]

7. Bridge, M. Locating the origins of wood resources: A review of dendroprovenancing. J. Archaeol. Sci. 2012, 39, 2828-2834. [CrossRef]

8. Li, H.Q.; Yu, Y.; Yu, X. On fire protection problems and its countermeasures about Chinese ancient architecture. Appl. Mech. Mater. 2012, 204, 3365-3368. [CrossRef]

9. Tang, Z. Does the institution of property rights matter for heritage preservation? Evidence from China. In Cultural Heritage Politics in China; Springer: New York, NY, USA, 2013; pp. 23-30.

10. Fregonese, L.; Barbieri, G.; Biolzi, L.; Bocciarelli, M.; Frigeri, A.; Taffurelli, L. Surveying and monitoring for vulnerability assessment of an ancient building. Sensors 2013, 13, 9747-9773. [CrossRef] [PubMed] 
11. Al-Kheder, S.; Al-Shawabkeh, Y.; Haala, N. Developing a documentation system for desert palaces in Jordan using 3D laser scanning and digital photogrammetry. J. Archaeol. Sci. 2009, 36, 537-546. [CrossRef]

12. Oreni, D.; Cuca, B.; Brumana, R. Three-dimensional virtual models for better comprehension of architectural heritage construction techniques and its maintenance over time. In Progress in Cultural Heritage Preservation; Springer: Berlin, Germany; Heidelberg, Germany, 2012; pp. 533-542.

13. Brumana, R.; Oreni, D.; Cuca, B.; Binda, L.; Condoleo, P.; Triggiani, M. Strategy for integrated surveying techniques finalized to interpretive models in a byzantine church, Mesopotam, Albania. Int. J. Archit. Herit. 2014, 8, 886-924. [CrossRef]

14. McCarthy, J. Multi-image photogrammetry as a practical tool for cultural heritage survey and community engagement. J. Archaeol. Sci. 2014, 43, 175-185. [CrossRef]

15. Martínez, S.; Ortiz, J.; Gil, M.L.; Rego, M.T. Recording complex structures using close range photogrammetry: The cathedral of Santiago De Compostela. Photogramm. Rec. 2013, 28, 375-395. [CrossRef]

16. Remondino, F. Heritage recording and 3D modeling with photogrammetry and 3D scanning. Remote Sens. 2011, 3, 1104-1138. [CrossRef]

17. Guarnieri, A.; Milan, N.; Vettore, A. Monitoring of complex structure for structural control using terrestrial laser scanning (TLS) and photogrammetry. Int. J. Archit. Herit. 2013, 7, 54-67. [CrossRef]

18. Ercoli, L.; Megna, B.; Nocilla, A.; Zimbardo, M. Measure of a limestone weathering degree using laser scanner. Int. J. Archit. Herit. 2013, 7, 591-607. [CrossRef]

19. Lambers, K.; Eisenbeiss, H.; Sauerbier, M.; Denise Kupferschmidt, D.; Gaisecker, T.; Sotoodeh, S.; Hanusch, T. Combining photogrammetry and laser scanning for the recording and modelling of the Late Intermediate Period site of Pinchango Alto, Palpa, Peru. J. Archaeol. Sci. 2007, 34, 1702-1712. [CrossRef]

20. Rüther, H.; Chazan, M.; Schroeder, R.; Neeser, R.; Held, C.; Walker, S.J.; Matmon, N.; Horwitz, L.K. Laser scanning for conservation and research of African cultural heritage sites: The case study of Wonderwerk Cave, South Africa. J. Archaeol. Sci. 2009, 36, 1847-1856. [CrossRef]

21. Lezzerini, M.; Antonelli, F.; Columbu, S. The documentation and conservation of the cultural heritage: 3D laser scanning and GIS techniques for thematic mapping of the stonework of the facade of St. Nicholas church (Pisa, Italy). Int. J. Archit. Herit. 2014. [CrossRef]

22. Chellini, G.; Nardini, L.; Pucci, B. Evaluation of seismic vulnerability of Santa Maria del Mar in Barcelona by an integrated approach based on terrestrial laser scanner and finite element modeling. Int. J. Archit. Herit. 2014, 8, 795-819. [CrossRef]

23. Pesci, A.; Casula, G.; Boschi, E. Laser scanning the Garisenda and Asinelli towers in Bologna (Italy): Detailed deformation patterns of two ancient leaning buildings. J. Cult. Herit. 2011, 12, 117-127. [CrossRef]

24. Kuzminsky, S.C.; Gardiner, M.S. Three-dimensional laser scanning: potential uses for museum conservation and scientific research. J. Archaeol. Sci. 2012, 39, 2744-2751. [CrossRef]

25. Pesci, A.; Bonali, E.; Galli, C. Laser scanning and digital imaging for the investigation of an ancient building: Palazzo d'Accursio study case (Bologna, Italy). J. Cult. Herit. 2012, 13, 215-220. [CrossRef]

26. Domingo, I.; Villaverde, V.; López-Montalvo, E. Latest developments in rock art recording: Towards an integral documentation of Levantine rock art sites combining 2D and 3D recording techniques. J. Archaeol. Sci. 2013, 40, 1879-1889. [CrossRef]

27. Hinzen, K.G.; Schreiber, S.; Rosellen, S. A high resolution laser scanning model of the Roman theater in Pinara, Turkey-Comparison to previous measurements and search for the causes of damage. J. Cult. Herit. 2013, 14, 424-430. [CrossRef]

28. Guidi, G.; Russo, M.; Angheleddu, D. 3D survey and virtual reconstruction of archeological sites. Digit. Appl. Archaeol. Cult. Herit. 2014, 1, 55-69. [CrossRef]

29. Remondino, F.; ElHakim, S. Image-based 3D modelling: A review. Photogramm. Rec. 2006, 21, $269-291$. [CrossRef]

30. Soudarissanane, S.; Lindenbergh, R.; Menenti, M. Scanning geometry: Influencing factor on the quality of terrestrial laser scanning points. ISPRS J. Photogramm. Remote Sens. 2011, 66, 389-399. [CrossRef]

31. Lei, Z.K.; Zhou, L.; Zheng, J.H. Preliminary study of building pathological information system for wall painting-in the case of Liang-Yi Temple at Wudang Mountain. Appl. Mech. Mater. 2012, 174, 1645-1650. [CrossRef]

32. Jun, Y.; Shaohua, W.; Jiayuan, L. Research on fine management and visualization of ancient architectures based on integration of 2D and 3D GIS technology. IOP Publ. 2014, 17, 012168. [CrossRef] 
33. Li, X.F.; Tao, H. Study on the digitalization and virtual restoration of the hall of Yuzhen Palace in Wudang Mountain. Archit. J. 2004, 12, 66-68.

34. Zhang, K.; Hu, C.S. World Heritage in China; South China University of Technology Press: Guangdong, China, 2006.

35. Gruen, A.; Akca, D. Least squares 3D surface and curve matching. ISPRS J. Photogramm. Remote Sens. 2005, 59, 151-174. [CrossRef]

36. Yin, X.; Wonka, P.; Razdan, A. Generating 3D building models from architectural drawings: A survey. IEEE Comput. Graph. Appl. 2009, 29, 20-30. [CrossRef] [PubMed]

37. Peng, T.; Gupta, S.K. Model and algorithms for point cloud construction using digital projection patterns. J. Comput. Inf. Sci. Eng. 2007, 7, 372-381. [CrossRef]

38. Yoo, D.J. Rapid surface reconstruction from a point cloud using the least-squares projection. Int. J. Precis. Eng. Manuf. 2010, 11, 273-283. [CrossRef]

39. Wu, Y.F.; Wong, Y.S.; Loh, H.T. Modelling cloud data using an adaptive slicing approach. Comput. Aided Des. 2004, 36, 231-240. [CrossRef]

40. Zhang, Y.F.; Wong, Y.S.; Loh, H.T. An adaptive slicing approach to modelling cloud data for rapid prototyping. J. Mater. Process. Technol. 2003, 140, 105-109. [CrossRef]

41. Manferdini, A.; Remondino, F. A review of reality-based 3D model generation, segmentation and web-based visualization methods. Int. J. Herit. Digit. Era 2012, 1, 103-124. [CrossRef]

42. Remondino, F.; Rizzi, A. Reality-based 3D documentation of natural and cultural heritage sites-Techniques, problems, and examples. Appl. Geomat. 2010, 2, 85-100. [CrossRef]

43. Apollonio, F.I.; Gaiani, M.; Benedetti, B. 3D reality-based artefact models for the management of archaeological sites using 3D Gis: A framework starting from the case study of the Pompeii Archaeological area. J. Archaeol. Sci. 2012, 39, 1271-1287. [CrossRef]

44. Guidi, G.; Remondino, F.; Russo, M. A multi-resolution methodology for the 3D modeling of large and complex archeological areas. Int. J. Archit. Comput. 2009, 7, 39-55. [CrossRef]

45. Toniolo, L.; Boriani, M.; Guidi, G. Built Heritage: Monitoring Conservation Management; Springer: Berlin, Germany, 2015.

46. Pieraccini, M.; Fratini, M.; Dei, D. Structural testing of Historical Heritage Site Towers by microwave remote sensing. J. Cult. Herit. 2009, 10, 174-182. [CrossRef]

47. Weritz, F.; Kruschwitz, S.; Maierhofer, C. Assessment of moisture and salt contents in brick masonry with microwave transmission, spectral-induced polarization, and laser-induced breakdown spectroscopy. Int. J. Archit. Herit. 2009, 3, 126-144. [CrossRef]

48. Mannes, D.; Schmid, F.; Frey, J. Combined neutron and X-ray imaging for non-invasive investigations of cultural heritage objects. Phys. Procedia 2015, 69, 653-660. [CrossRef] 